\title{
LA-UR-20-22799
}

Approved for public release; distribution is unlimited.

Title: Defects and Mechanical Behavior of Plutonium

Author(s): $\quad$ Jacobs, Taylor Roth; Gibbs, Meghan Jane; Yablinsky, Clarissa Ann; Freibert, Franz Joseph; Hernandez, Sarah Christine; Mitchell, Jeremy Neil; Saleh, Tarik A.; Kral, Gabrielle Anne; Solis, Eunice Martinez; Imhoff, Seth D.; Bridgewater, Jon S.; Teter, David Fredrick

Intended for: $\quad$ LANL seminar (to be presented online due to work from home status)

Issued: $\quad$ 2020-04-08 
Disclaimer:

Los Alamos National Laboratory, an affirmative action/equal opportunity employer, is operated by Triad National Security, LLC for the National Nuclear Security Administration of U.S. Department of Energy under contract 89233218CNA000001. By approving this article, the publisher recognizes that the U.S. Government retains nonexclusive, royalty-free license to publish or reproduce the published form of this contribution, or to allow others to do so, for U.S. Government purposes. Los Alamos National Laboratory requests that the publisher identify this article as work performed under the auspices of the U.S. Department of Energy. Los Alamos National Laboratory strongly supports academic freedom and a researcher's right to publish; as an institution, however, the Laboratory does not endorse the viewpoint of a publication or guarantee its technical correctness. 


\section{Defects and Mechanical Behavior of Plutonium}

\section{Taylor R. Jacobs}

Meghan Gibbs, Clarissa Yablinsky, Franz Freibert, Sarah Hernandez, Jeremy Mitchell, Tarik Saleh, Gabrielle Kral, Eunice Solis, Seth Imhoff, John Bridgewater, Dave Teter

\section{MST-16 Seminar}

$2 / 11 / 2020$

- Los Alamos

NATIONAL LABORATORY

Noside 


\section{Personal Background}

- 2013: BS in Metallurgy and Materials Engineering from the Colorado School of Mines.

- 2013: Metallurgist intern at Nucor Steel.

- Steel continuous casting, hot/cold rolling, and heat treatment production operations.
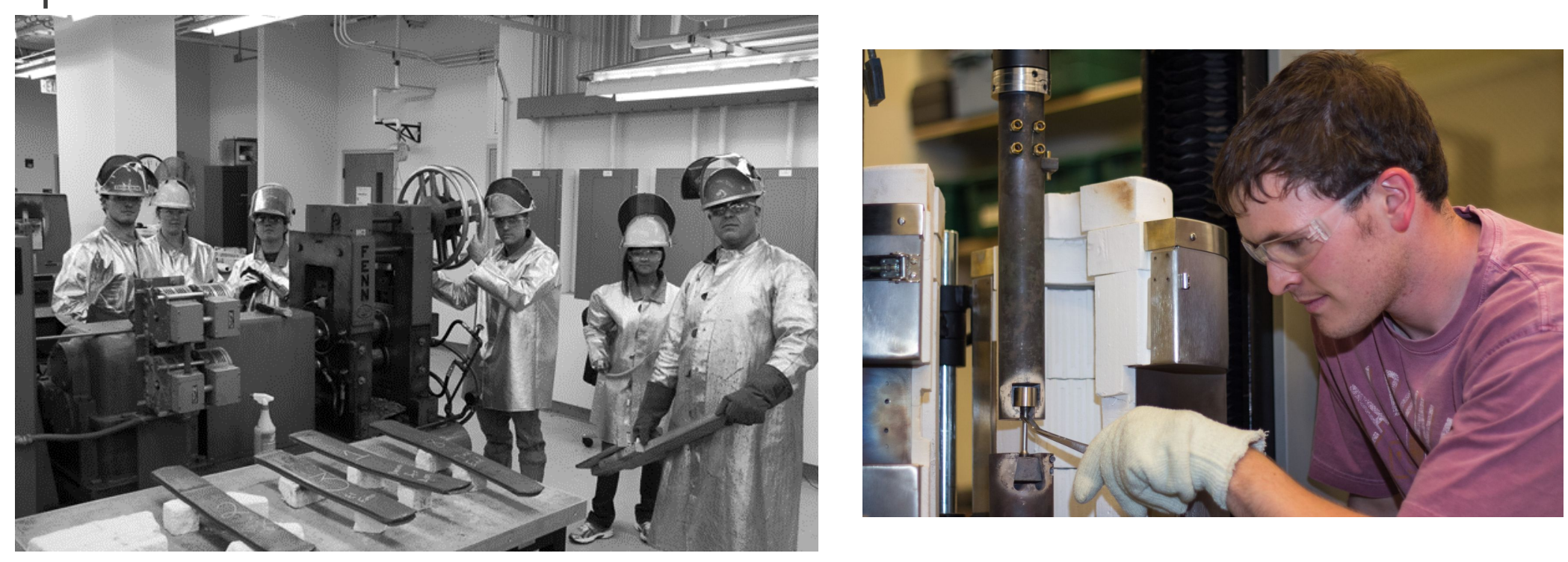


\section{Personal Background}

- 2015/2018: MS and PhD in Metallurgy and Materials Engineering from the Colorado School of Mines.

- Microstructure/property relationships of steels at elevated temperatures.

- Foundry, mechanical testing, and forming of various metals as a TA.

Dynamic Strain Aging (Dislocation Theory)

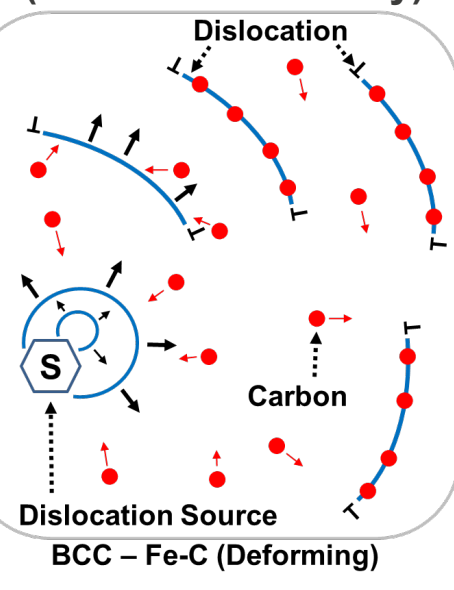

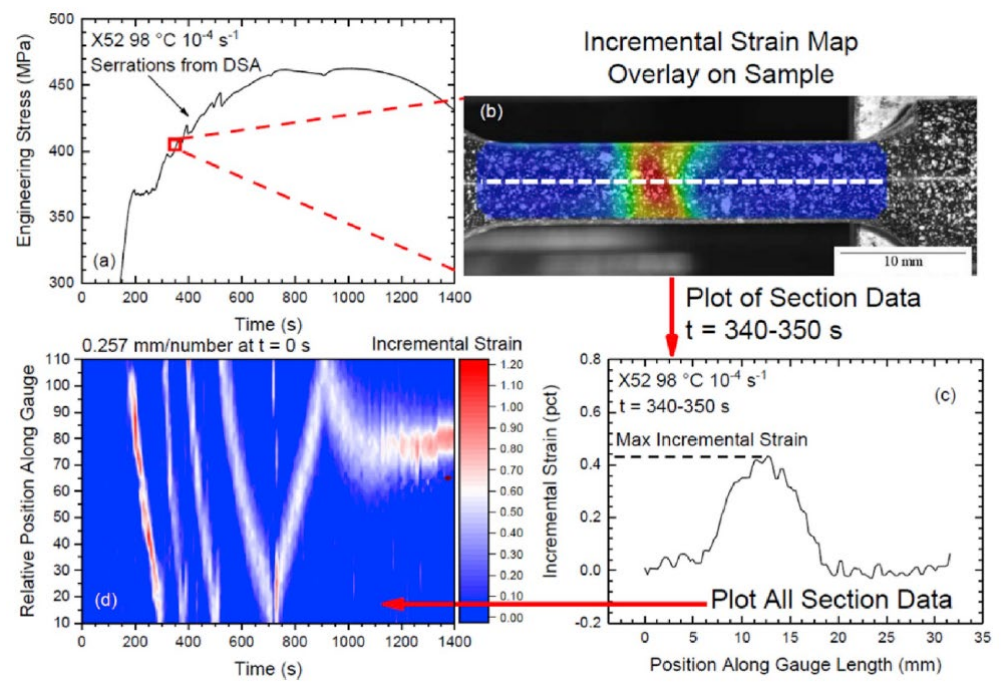

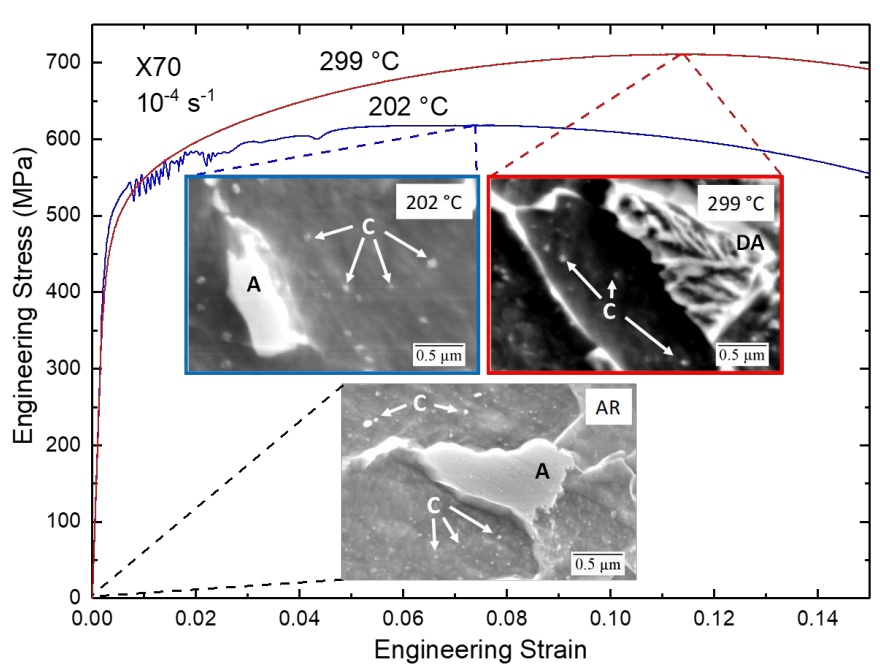




\section{Personal Background}

- 2018-2019: Postdoc at Los Alamos National Laboratory (MST-16)

- Characterization of Au-Zn-Al alloys.

- Early development of internal friction capabilities for Pu characterization at LANL.
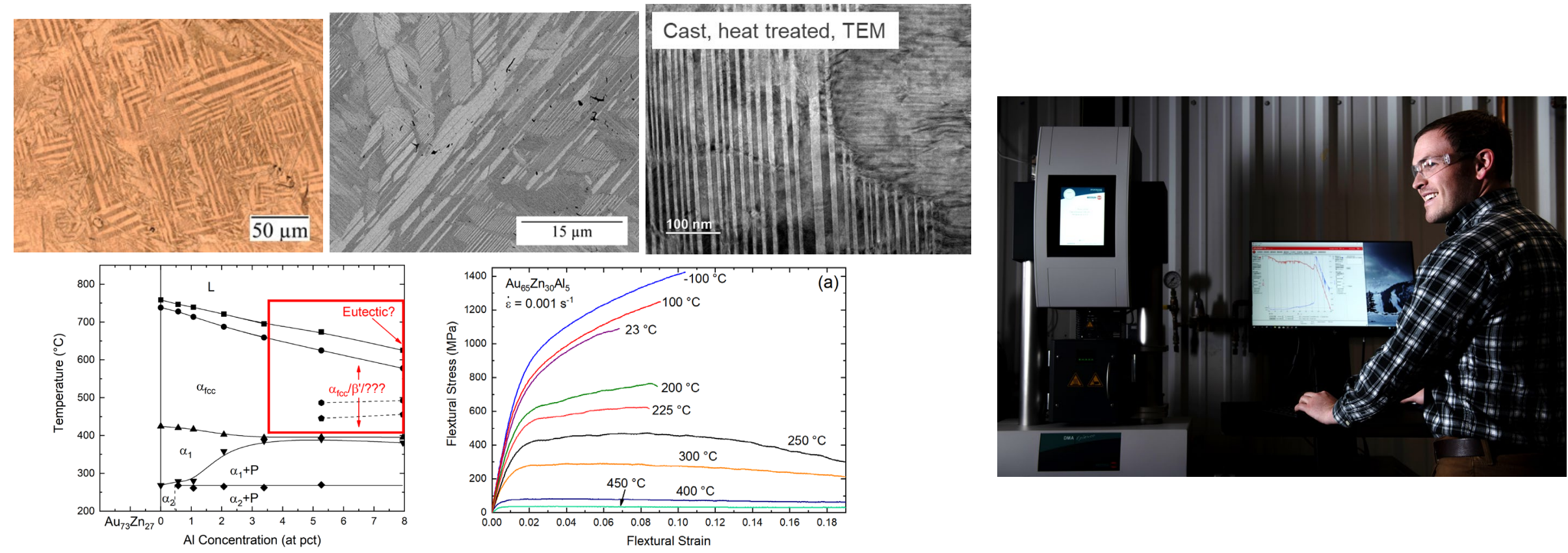

Al Concentration (at pct) 


\section{Introduction}

- Defects are important because they heavily influence material properties.

- Ex: Strength, ductility, elasticity, conductivity, phase transformation temperatures (melting point), corrosion resistance...

- At LANL defects in plutonium are being characterized using many different methods.

-Ex: EXAFS, XRD, microscopy, RUS, DSC, dilatometry, density...

- My goal: Introduce a complimentary method of understanding defects in $\delta$-Pu using the mechanical microscope concept.

- "Mechanical microscope" - John Jonas, 1998 Barret Award Lecture

- Using well-developed theories of first principles strengthening mechanisms (i.e. how defects influence strength) and carefully designed experiments, mechanical testing can compliment other defect characterization tools. 


\section{Mission Relevance}

- The creation of materials with application-tailored properties through the careful control of defects is part of the Materials for the Future: Actinides and Correlated Electron Materials Science Pillar at LANL.

- Goal: Fundamentally evaluate how plutonium defects influence material properties using mechanical deformation as a probe.

- We must first build fundamental knowledge of how Pu behaves using mechanical characterization techniques. (There are scarce data in this area).

-We can then use new understandings of defects to assess aging, performance, and production quality.

- Some of the parameters experimentally measured with these methods can directly support modeling efforts. 


\section{What is a Defect?}

- A defect is anything in a crystal that interrupts the long range order of the crystal structure.

ठ-Pu: FCC Unit Cell Perfect Single Crystal

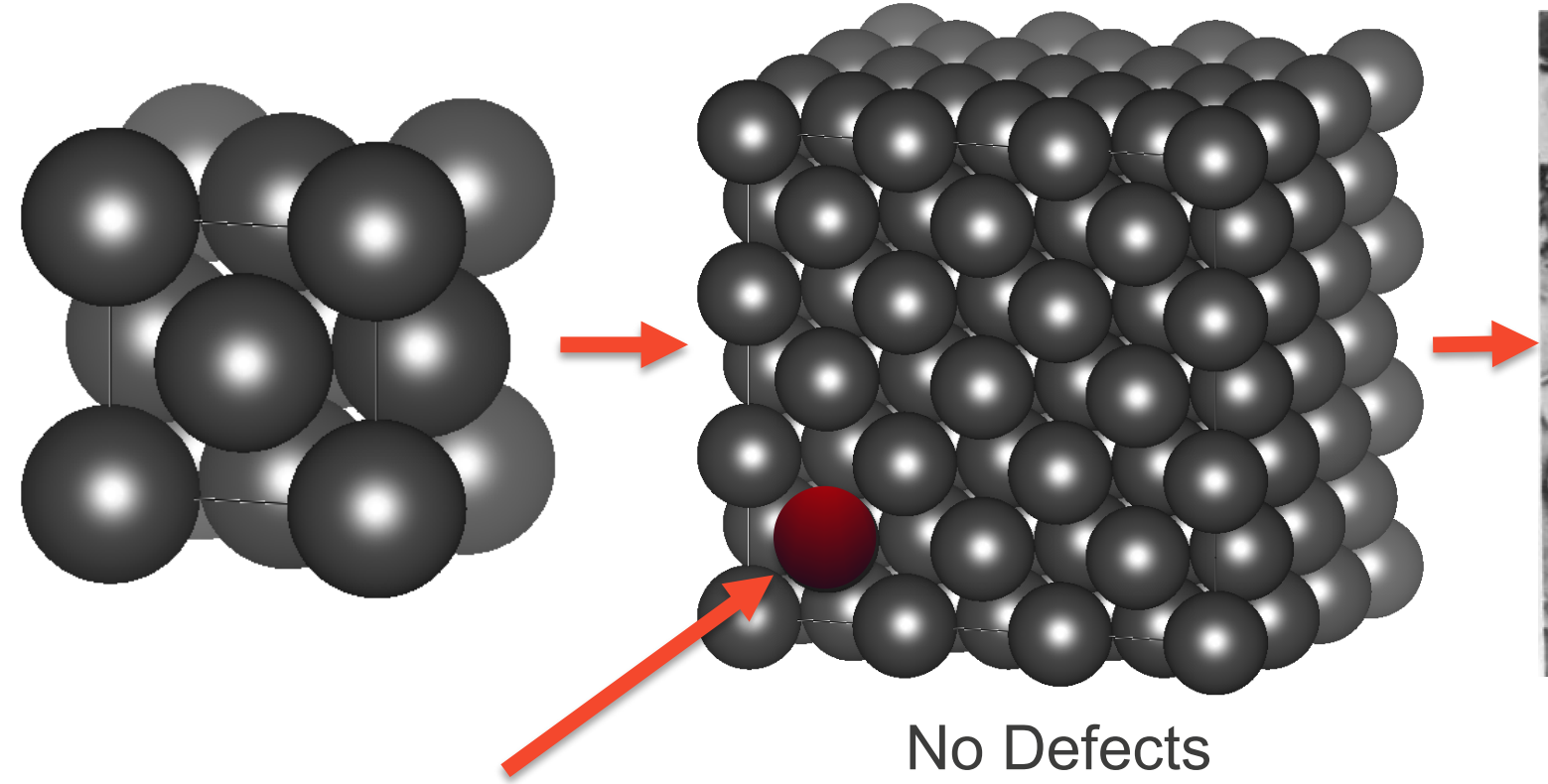

Substitutional Solute Defect
$\delta$-Pu Polycrystal

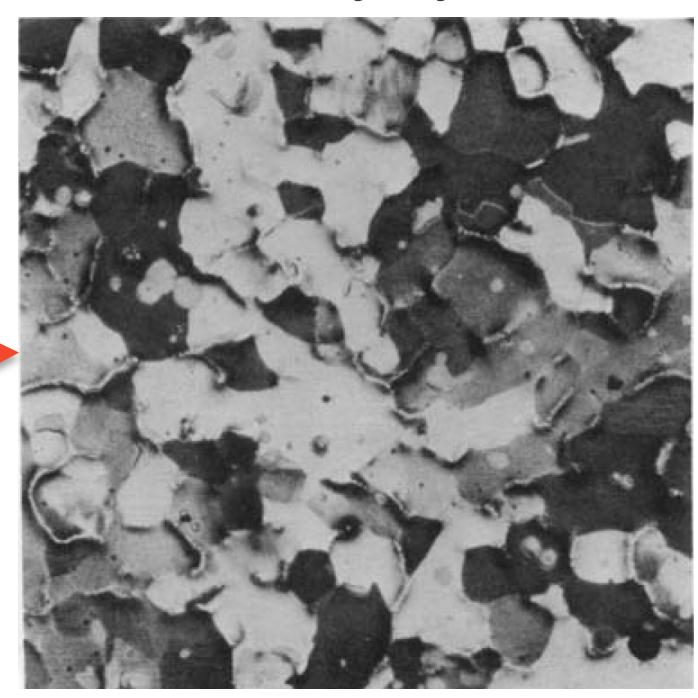

Grain Defects

H.R. Gardner, 1965 


\section{Common Defects in $\delta$-Plutonium}

- $\delta$-Pu is stabilized with Ga.

- Ga atoms are in solid solution.

- Decay products and impurity atoms from processing are also in solid solution.

- Dislocations.

- Helium bubbles.

- Inclusions.

- Grain boundaries.

- Second phases (Fe/Ni intermetallics). All of these defects can influence the properties of $\delta-P u ! ! !$

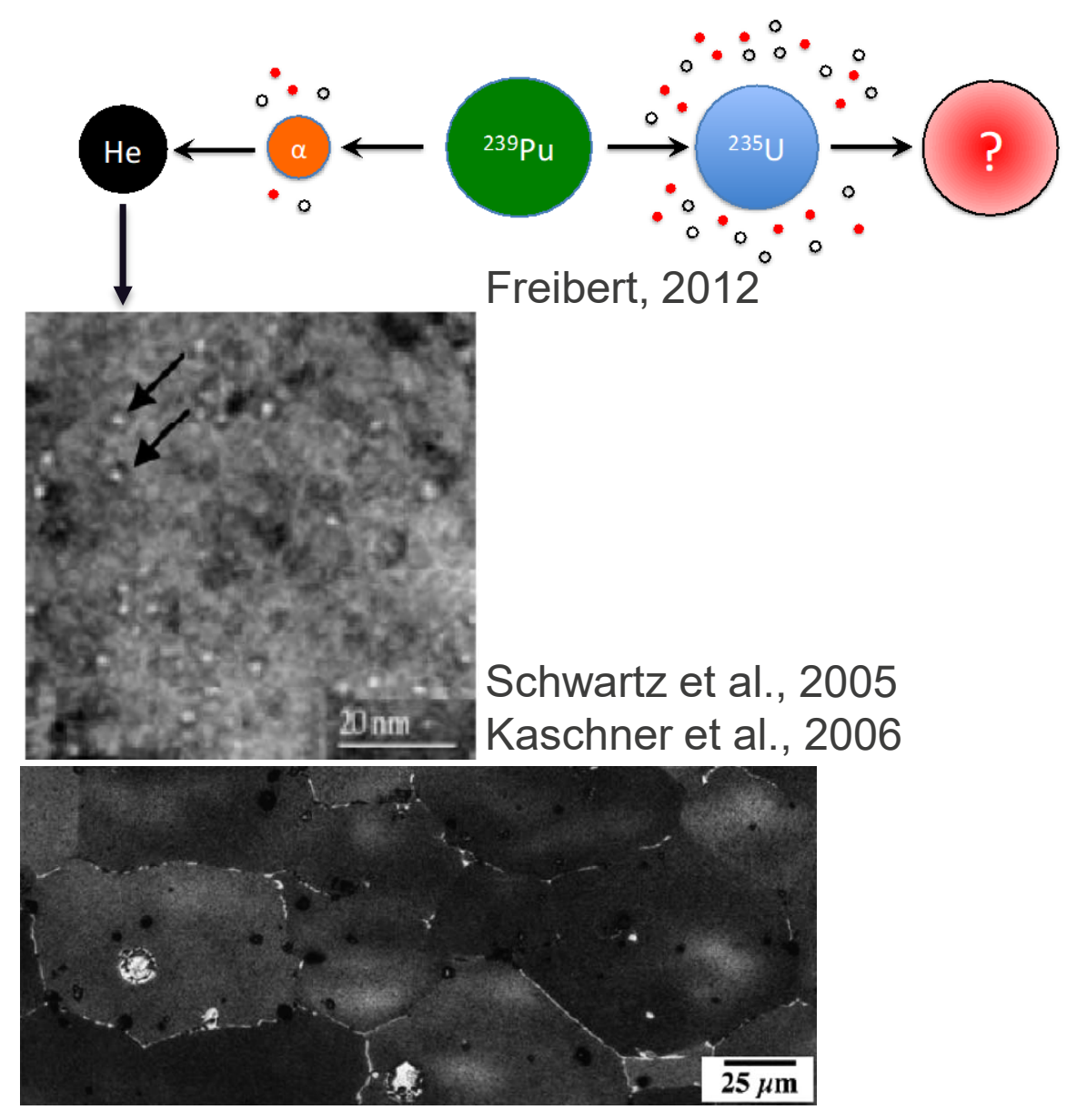




\section{How to Characterize Materials/Defects}

1. Cause a probe to interact with a material.

2. Use a detector to gather information from a signal caused by an interaction between the probe and material.

3. Analyze the information with fundamental knowledge of the system.

Needles used to test $\mathrm{Au} / \mathrm{Ag}$ ratios in an ore assay processes (de re Metallica, 1556).

Probe $=$ visible light

Signal $=$ color

Analysis $=$ ore grade
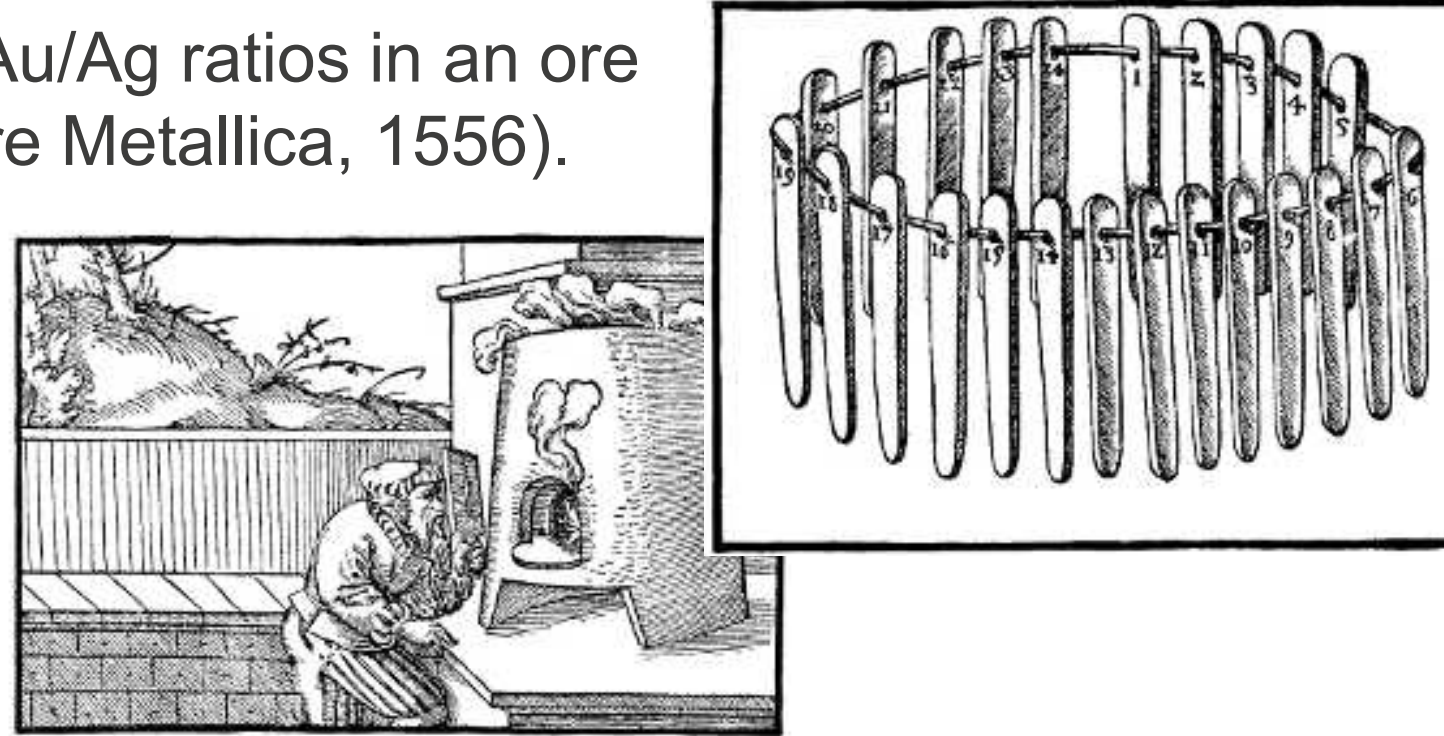


\section{Modern Examples}

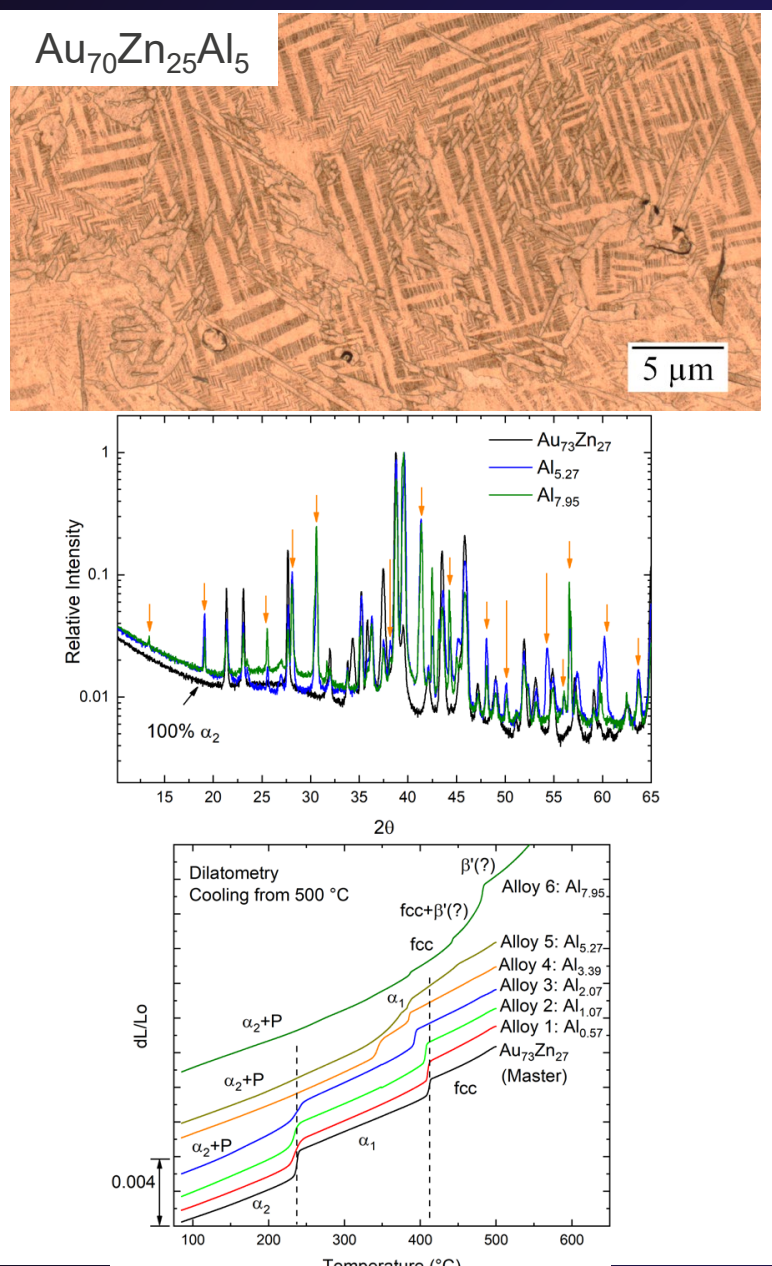

- Optical microscope

- Probe $=$ light $\mid$ Signal $=$ image

- Analysis: microstructure, grain size, morphologies, and phase volume fraction.

- X-ray diffraction

- Probe $=\mathrm{x}$-rays $\mid$ Signal $=$ diffracted $\mathrm{x}$-rays

- Analysis: crystal structure, lattice parameters, dislocation density, and phase volume fraction.

- Dilatometry

- Probe $=$ temperature $\mid$ Signal $=$ volume change

- Analysis = phase transformations, thermal expansion, phase volume fraction. 


\section{Modern Examples}

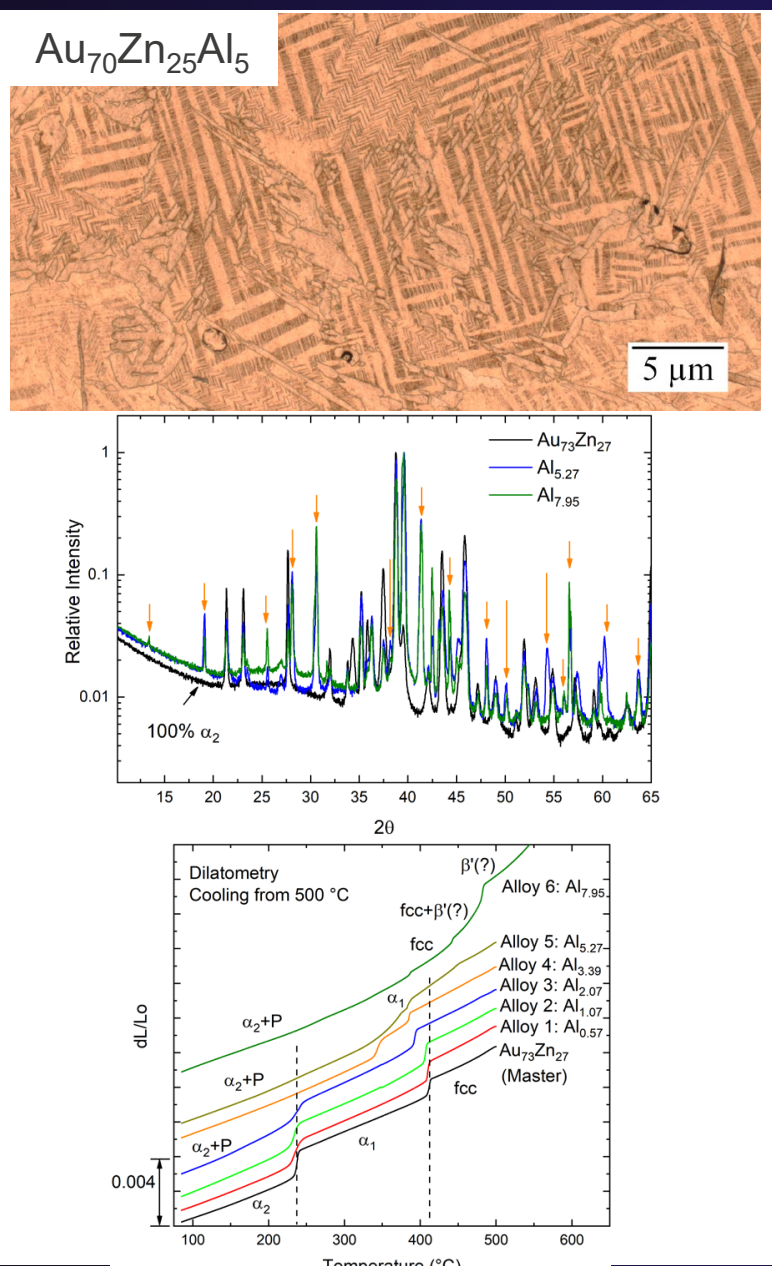

- Optical microscope

- Probe $=$ light $\mid$ Signal $=$ image

- Analysis: microstructure, grain size, morphologies, and phase volume fraction.

- X-ray diffraction

- Probe $=\mathrm{x}$-rays $\mid$ Signal $=$ diffracted $\mathrm{x}$-rays

- Analysis: crystal structure, lattice parameters, dislocation density, and phase volume fraction.

- Dilatometry

- Probe $=$ temperature $\mid$ Signal $=$ volume change

- Analysis = phase transformations, thermal expansion, phase volume fraction. 


\section{The Mechanical Microscope Concept}

- Uses mechanical deformation as a probe to study how microstructural defects influence strength (our signal).

- This is different from simply measuring strength (Ex: yield strength).

- Like many characterization techniques, we need a fundamental understanding of what defects can be present and how they influence our signal (strength).

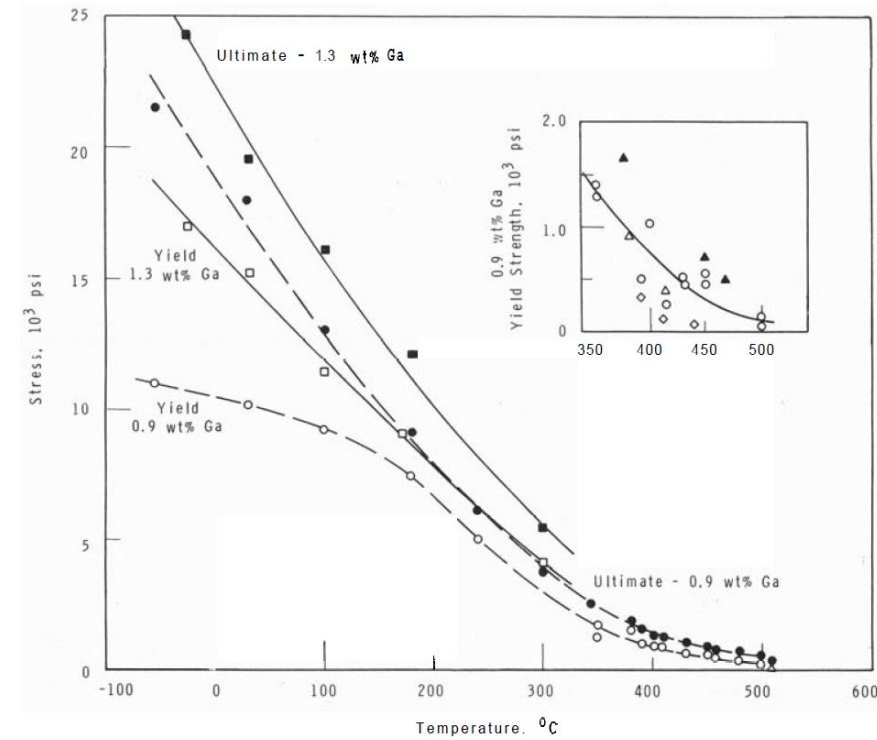

Strength as a function of temperature for $\delta$-stabilized Pu-Ga alloys.

H.R. Gardner, 1965 


\section{Theoretical Strength of $\delta-P u$}

- To achieve permanent deformation you need to physically shear 2 planes of atoms.

- Maximum strength is proportional to the shear modulus.

$$
\tau_{\text {Max }} \cong \frac{G}{2 \pi}
$$

- $\delta$-Pu Shear Modulus (G) $=15.8 \mathrm{GPa}$

- Theoretical strength of $\delta-\mathrm{Pu} \sim 2.5 \mathrm{GPa}$ $-2.5 \mathrm{GPa}=\mathbf{2 , 5 0 0 \mathrm { MPa }}$

- RT shear strength of $\delta-\mathrm{Pu}=74 \mathrm{MPa}$ - 34 times less than theoretical strength.

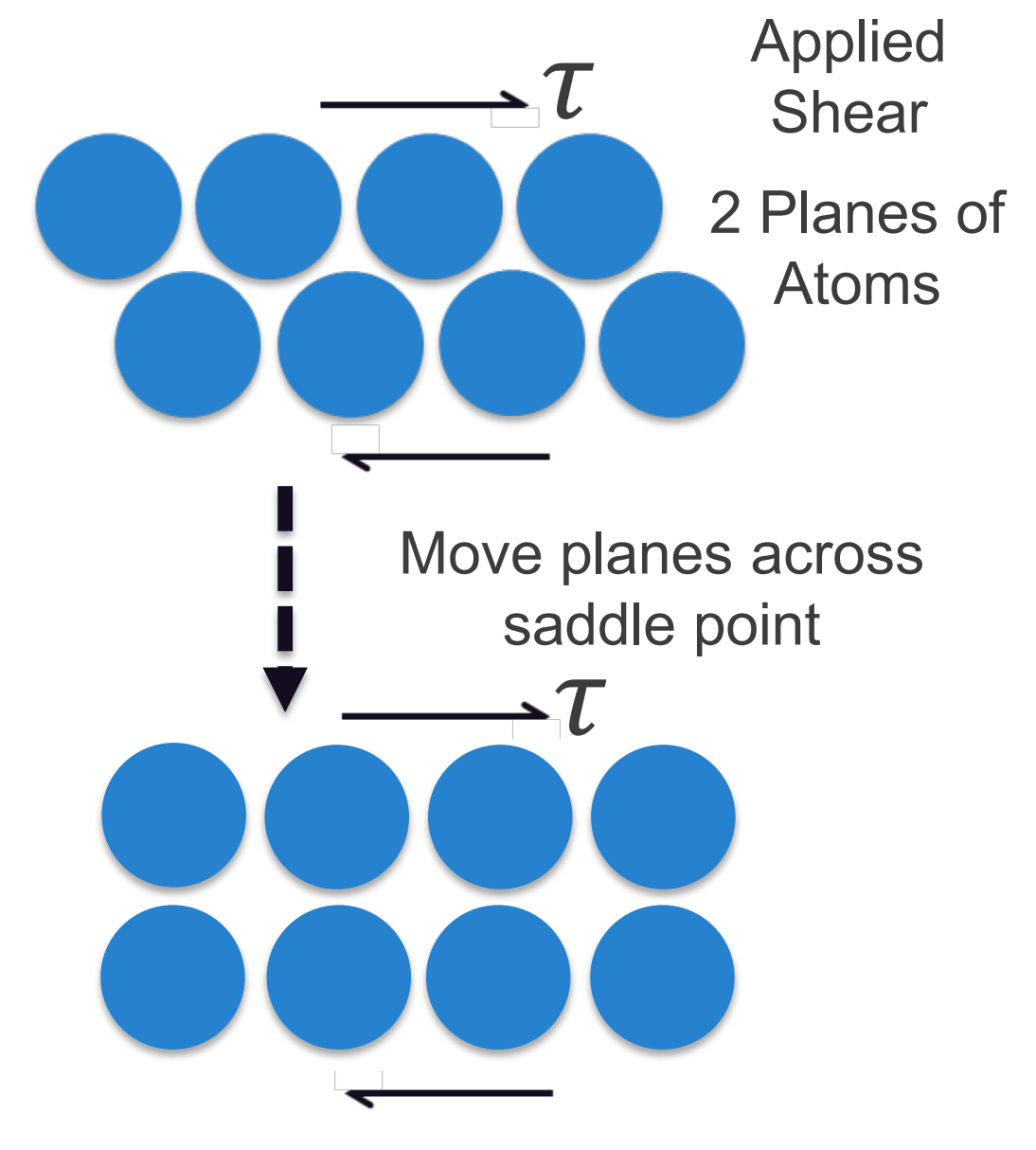

De Cooman and Findley, 2017; H.R. Gardner, 1965 


\section{Dislocations}

- Extra half plane of atoms in a crystal.

- Dislocations can be mobile causing displacements up to one Burger's vector $\left(b_{\delta-P u}=0.328 \mathrm{~nm}\right)$.

- It is easier to move dislocations than to shear entire planes of atoms (actual strength is lower than the theoretical strength).

- Material strength is directly related to how difficult it is to move dislocations.

- Defects in a crystal can impede dislocation motion, making the material stronger.

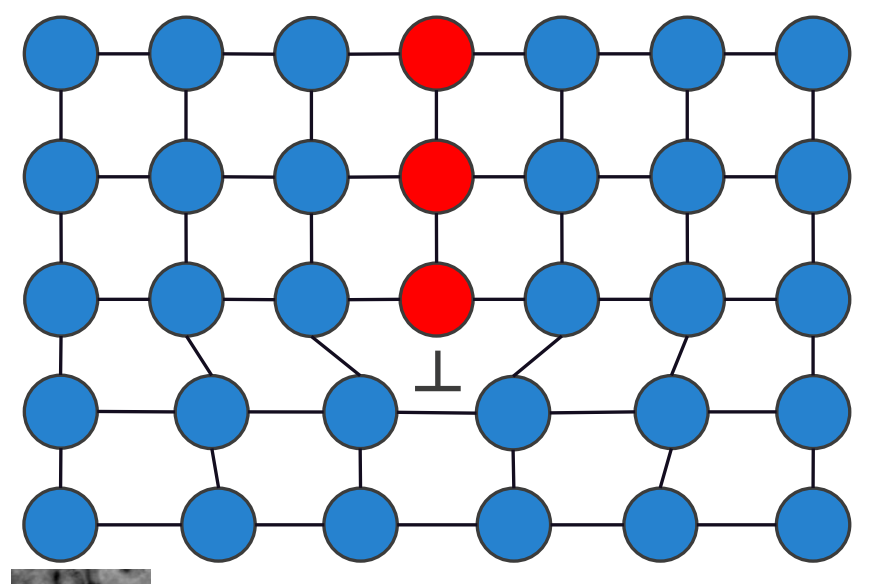

STEM: Dislocations in X70 Steel

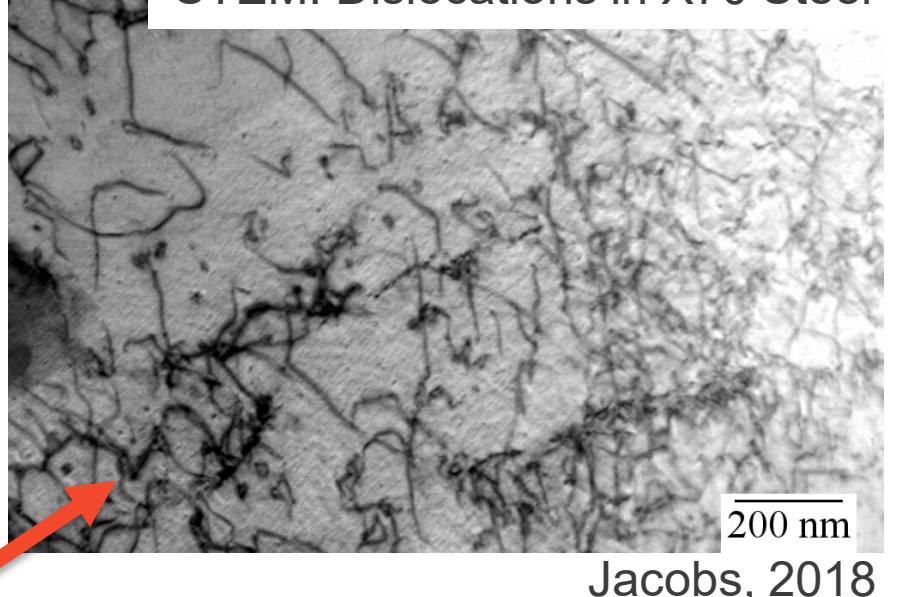




\section{Defects that can Interact with Dislocations}

- Other dislocations (D), solute atoms (S or I), grain boundaries "(GB), other phases $(P)$, surfaces, vacancies ( $V$, very weak).

- Some $\delta$-Pu defects: Ga, impurity atoms, decay products, He bubbles.

- Most of the time, the presence of defects increases strength.

- Dislocations must overcome the defect to continue moving.

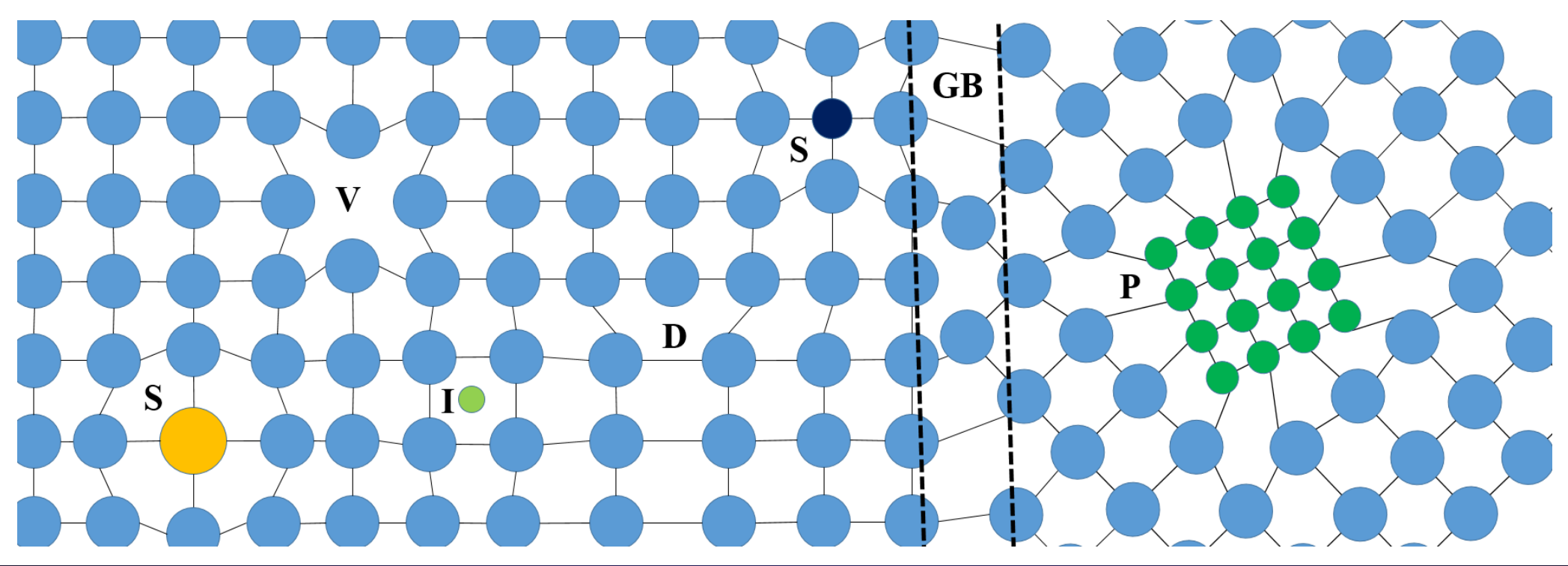




\section{Strength, Elasticity, and Plasticity}

- Strength:

- A measure of how a material can resist being deformed from its original shape.

- Two types of deformation (our probe)

1. Elastic = fully recoverable (bond stretching).

2. Plastic $=$ permanent deformation (generation and motion of dislocations).

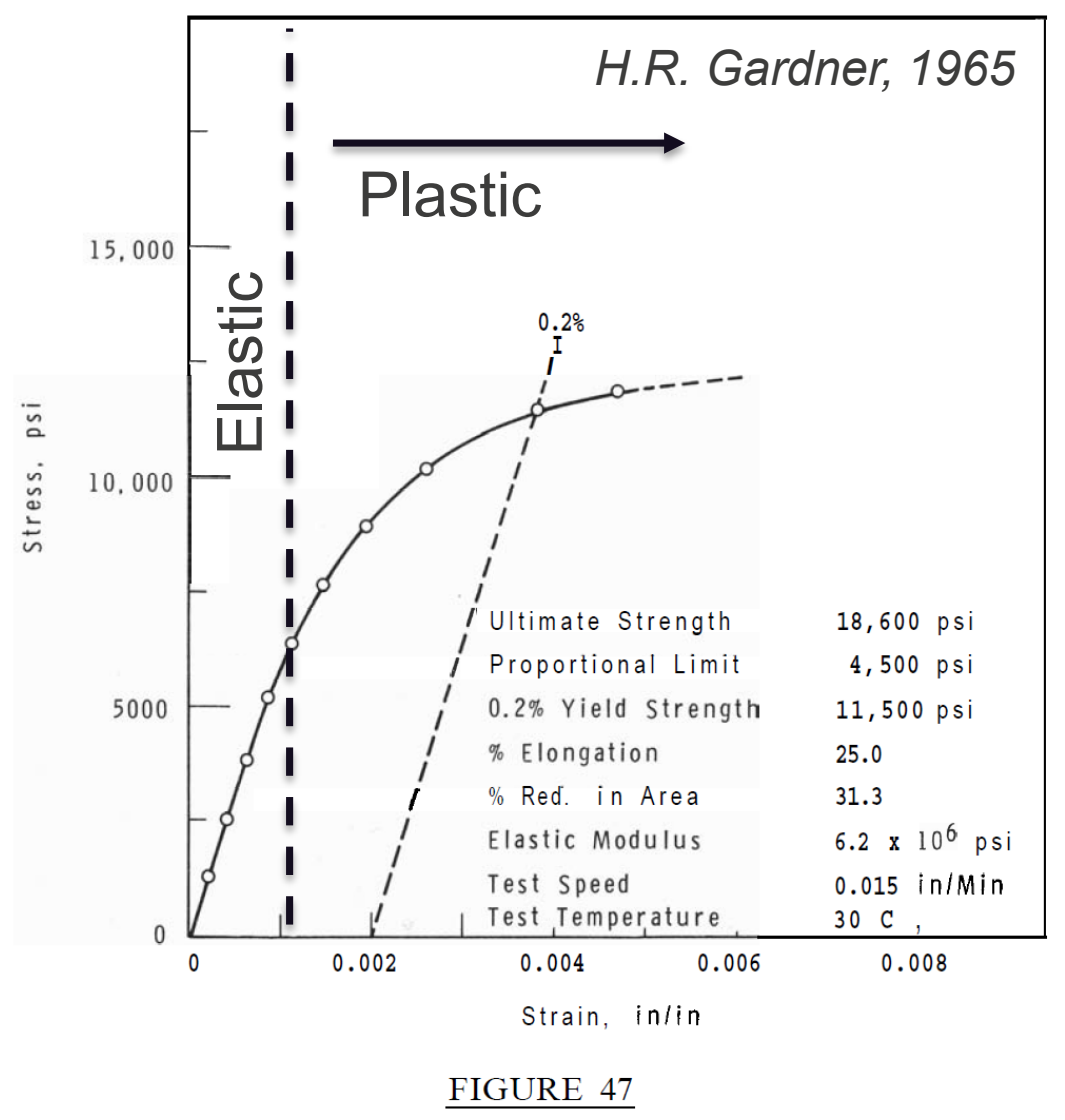




\section{Techniques Proposed for the "Mechanical Microscope"}

Analysis

1. Stress Relaxation:

- Probe $=$ dislocations (plastic deformation)

- Signal $=$ exponential load decay

- Analysis = activation volume, quantification of internal/effective stresses

2. Internal Friction:

- Probes $=$ Elastic strain vibrations and temperature

- Signal $=$ Vibration damping

- Analysis $=$ Defect mobility and phase transformations
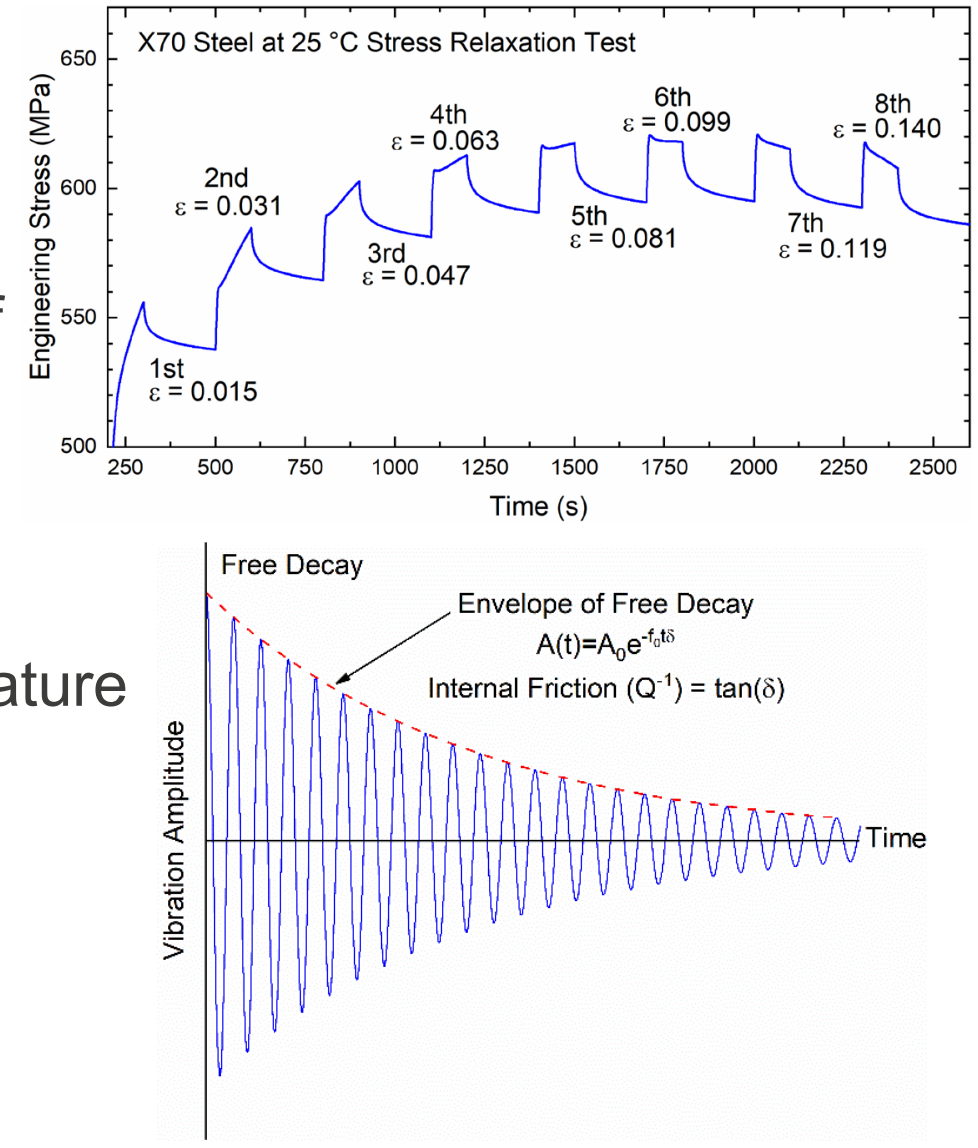


\section{Stress Relaxation}

(Using dislocation theory and mechanical behavior to

understand defect interactions)

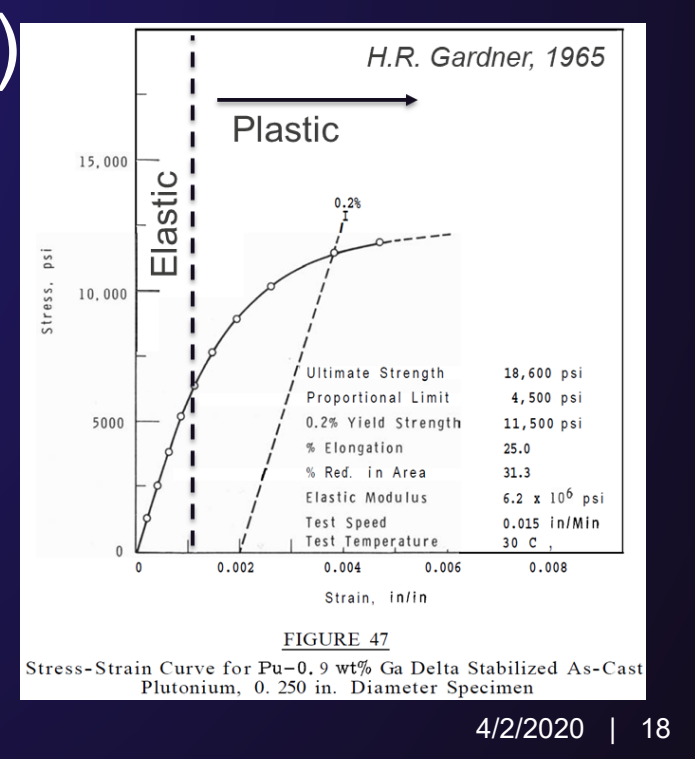




\section{The Stress Relaxation Test}
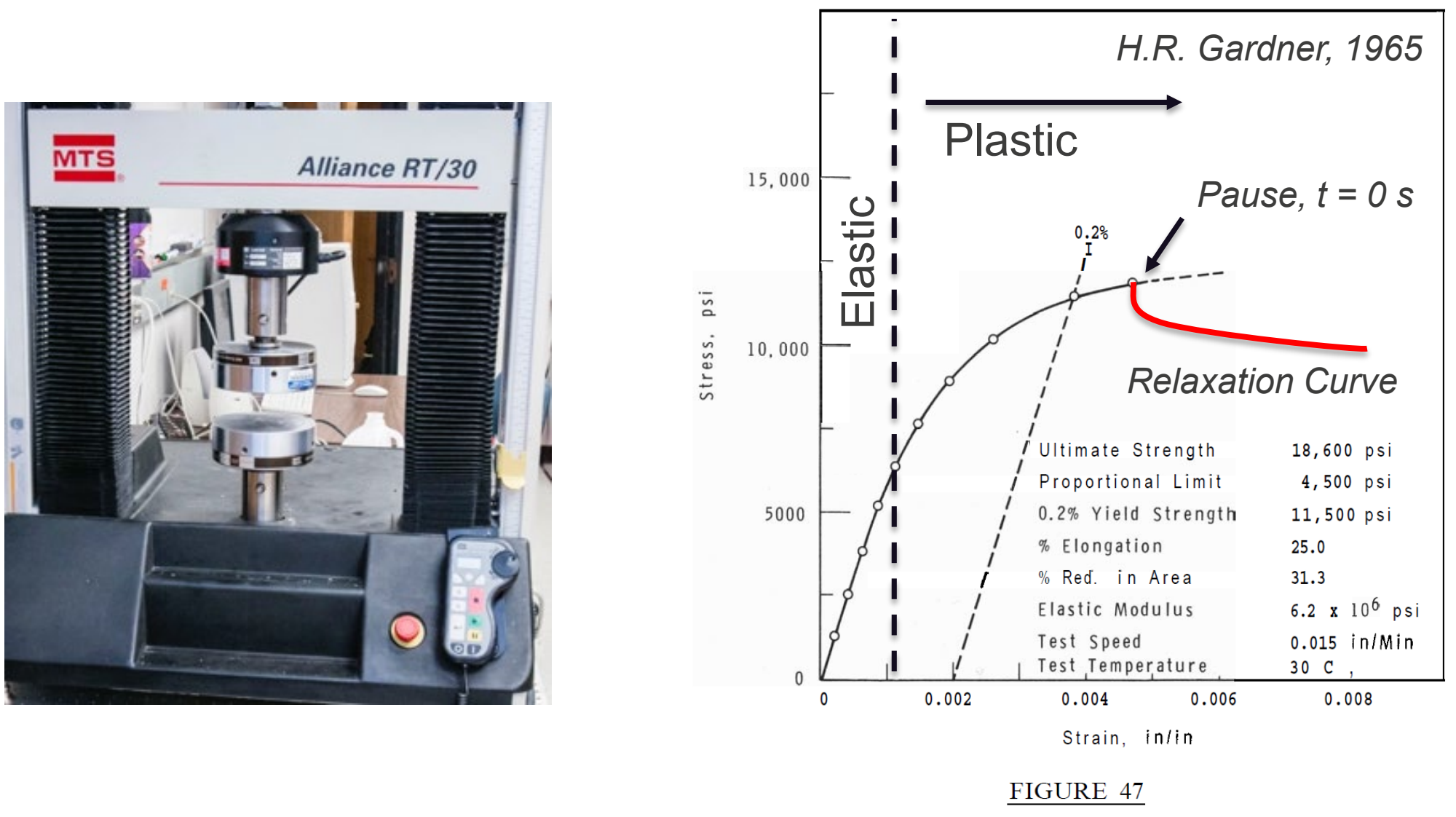

Stress-Strain Curve for Pu-0. 9 wt \% Ga Delta Stabilized As-Cast Plutonium, 0. 250 in. Diameter Specimen 


\section{Material Properties from Stress Relaxation}

- Flow stress = stress required for plastic deformation.

- Flow stress components:

- Thermal (effective stress)

- Short range stress fields

- 1 Burgers Vector $\left(b_{\delta-P u}=\right.$ 0.328)

- Athermal (internal stress)

- Long range stress fields

- Multiple atoms spacing's to grain size
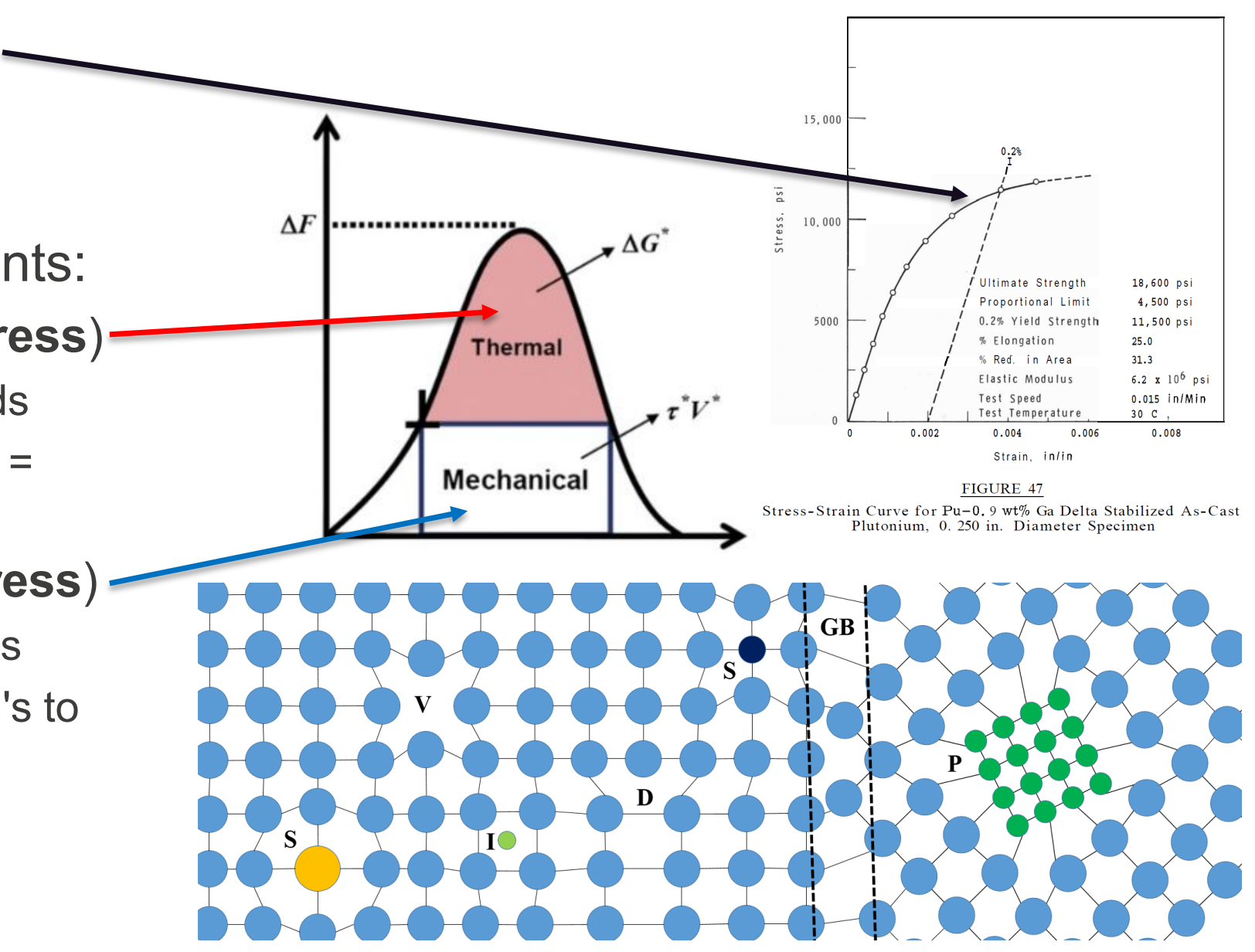


\section{Typical Stress Relaxation Responses}

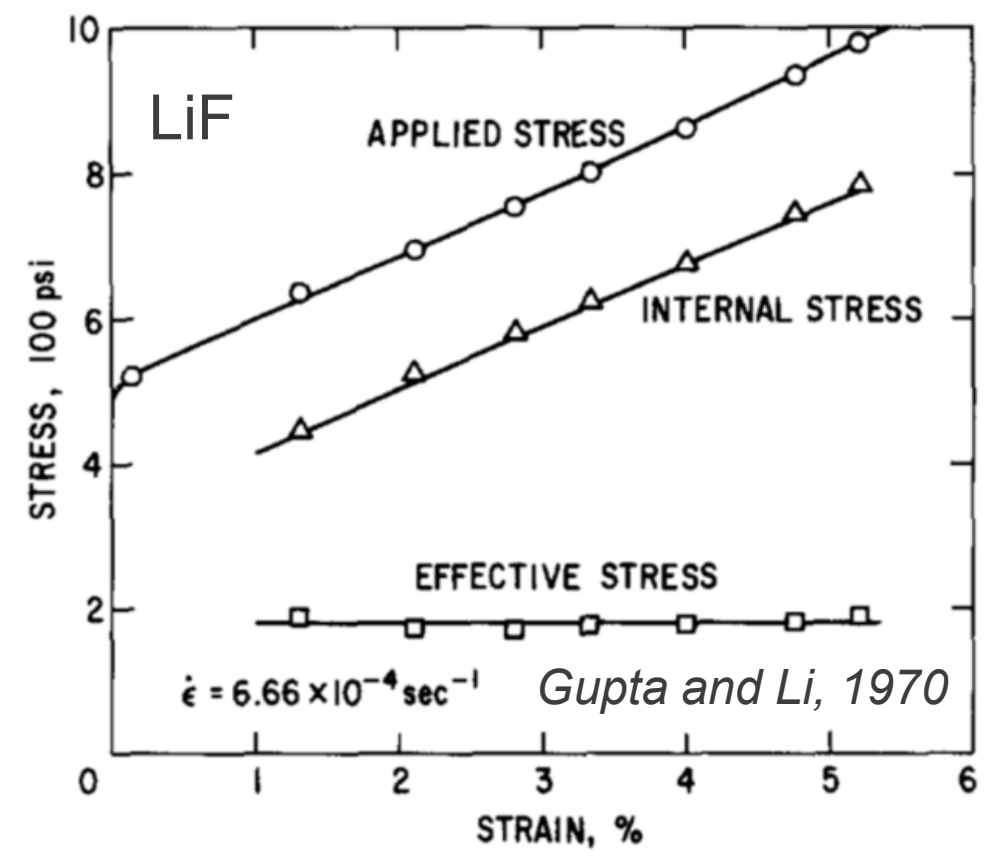

- Internal stress increases w/ strain

- Strain hardening from dislocation pileups at grain boundaries.

- Effective stress is constant

- Solid solution strengthening and the Peierls stress are typically strain independent (with some exceptions). 


\section{Activation Volume}

- The small volume of material involved in the event of a dislocation passing an obstacle.

- Used to identify the deformation mechanism.

- The presence of certain defects can have minor influences on $\mathrm{V}_{\text {act }}$.

FCC (ס-Pu): $100-1000 b^{3}=3.5-35 n^{3} \quad$ BCC $(\varepsilon-P u): 1-100 b^{3}$

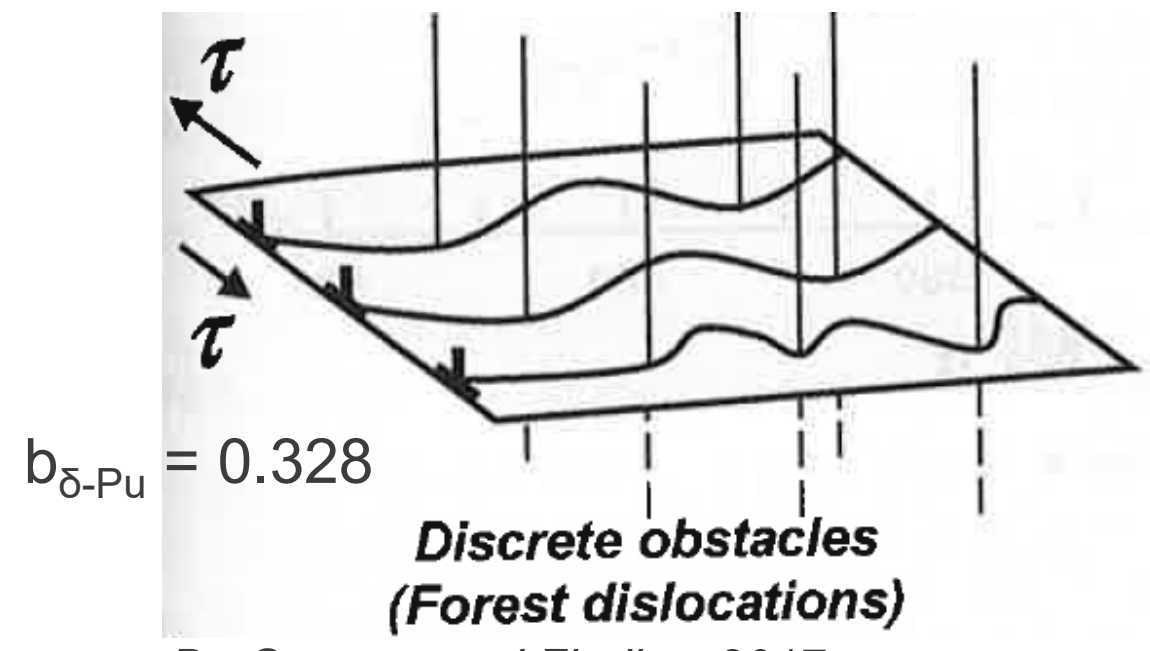

De Cooman and Findley, 2017

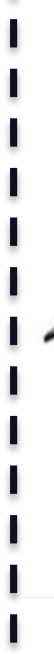

$\frac{\mathrm{a}}{2}\langle 111\rangle$ Screw Dislocation

$$
V_{a c t}=b * d * L \cong 1-100
$$




\section{The Stress Relaxation Test (Steel Example)}

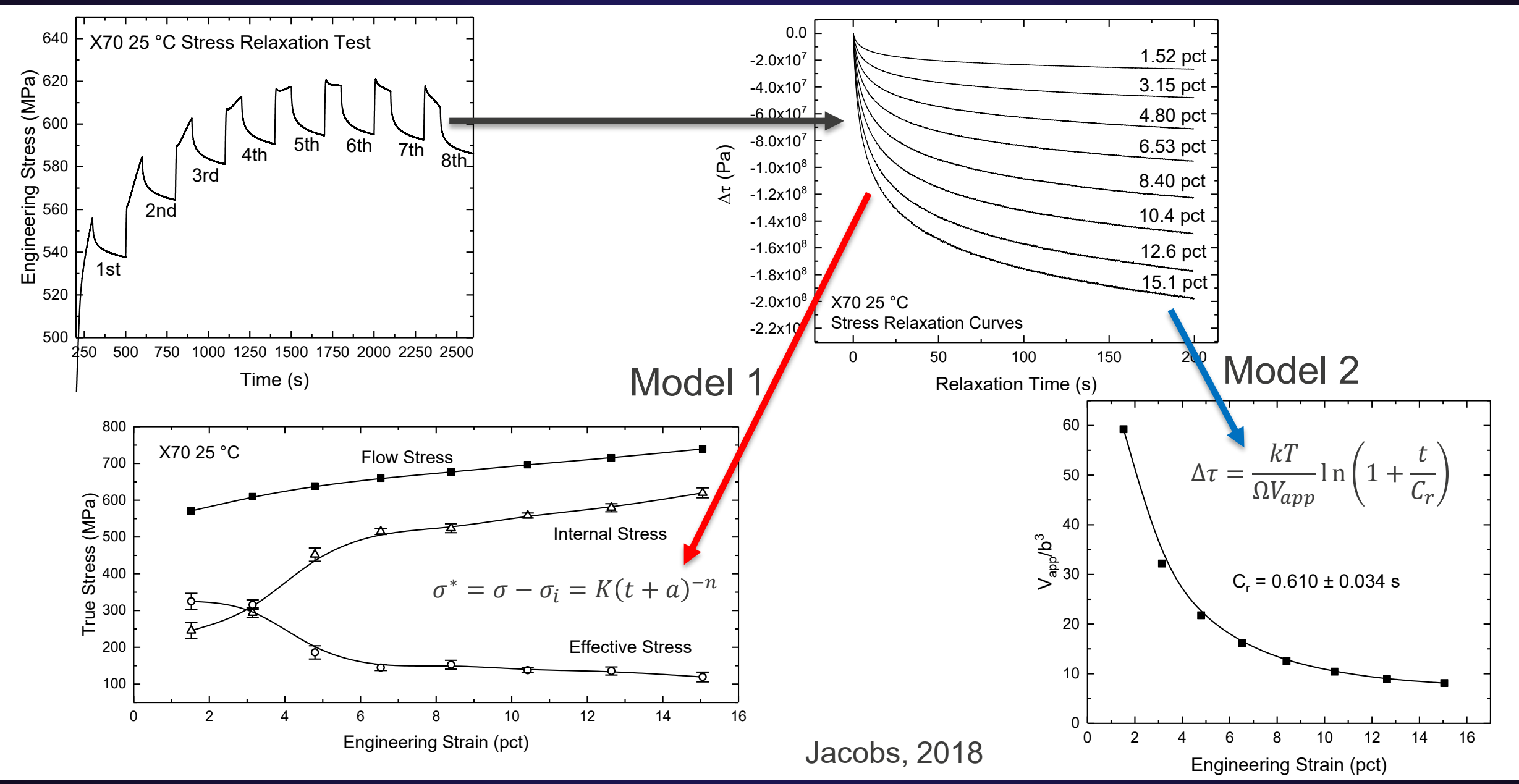




\section{Strengthening Mechanisms (Steel Example)}

- Contributions to effective stress:

- Peierls stress (PN): $\frac{a}{2}\langle 111\rangle$ screw dislocations (D)

$-\mathrm{C}$ and $\mathrm{N}$ interstitials

- Mn, Si, Cu, P, Ni, Mo substitutionals

- Contributions to the internal

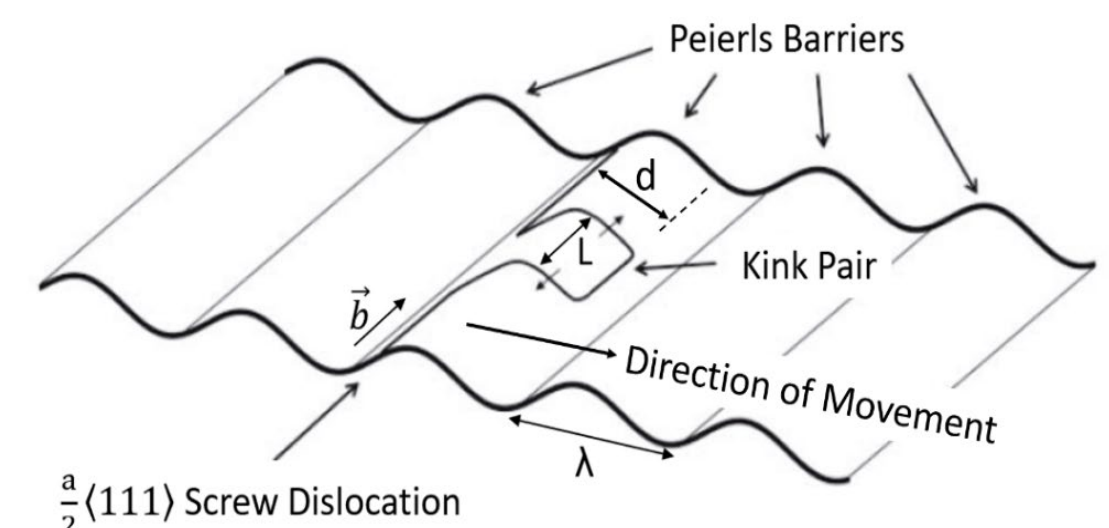
stress:

- Dislocation pileup at grain boundaries

- Precipitates (carbides and nitrides)

- Second phases (austenite/martensite)

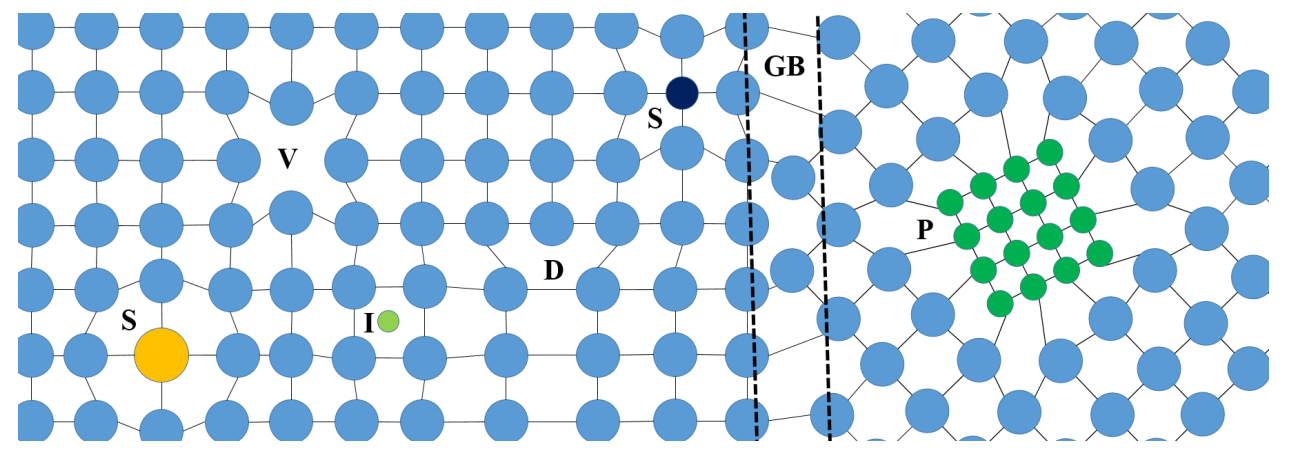




\section{Internal and Effective Stress Analysis (Steel Example)}

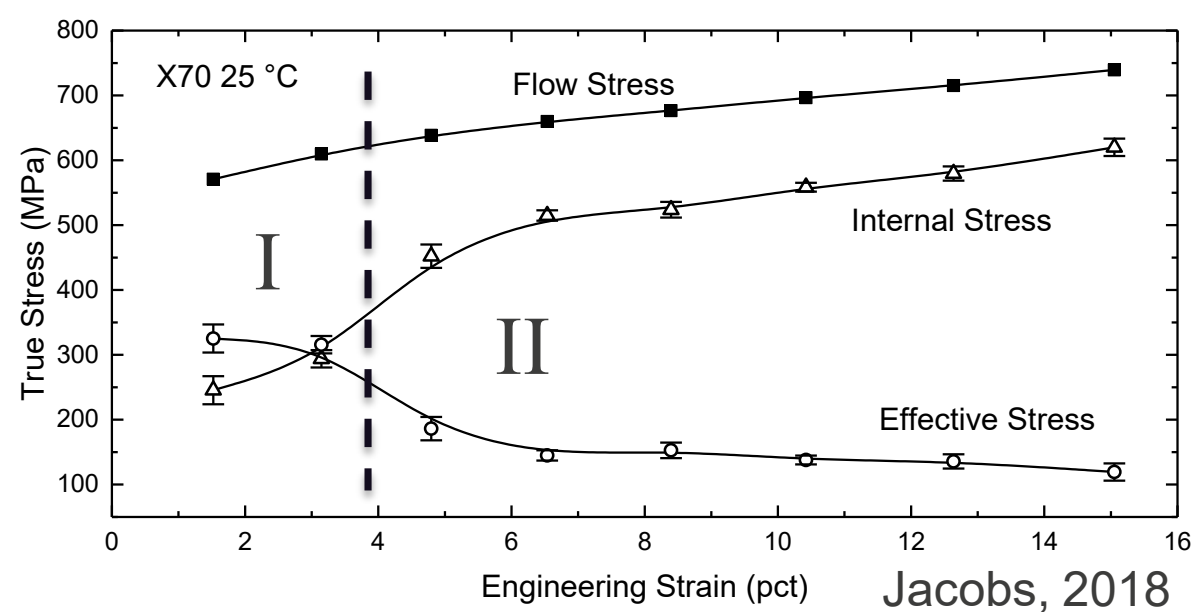

- Region I

- Abnormally high effective stress

- Region II

- Typical behavior of the effective/internal stresses.
- Static Strain Aging (Region I):

- Prior to deformation, solute atoms are mobile enough to diffuse to dislocations and pin them (impeding dislocation motion).

- To cause deformation, the dislocations must break away from the solutes.

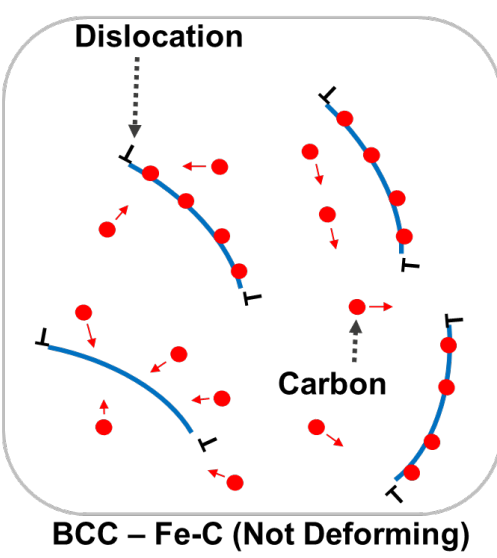




\section{Quantitative Analysis of Internal/Effective Stress}

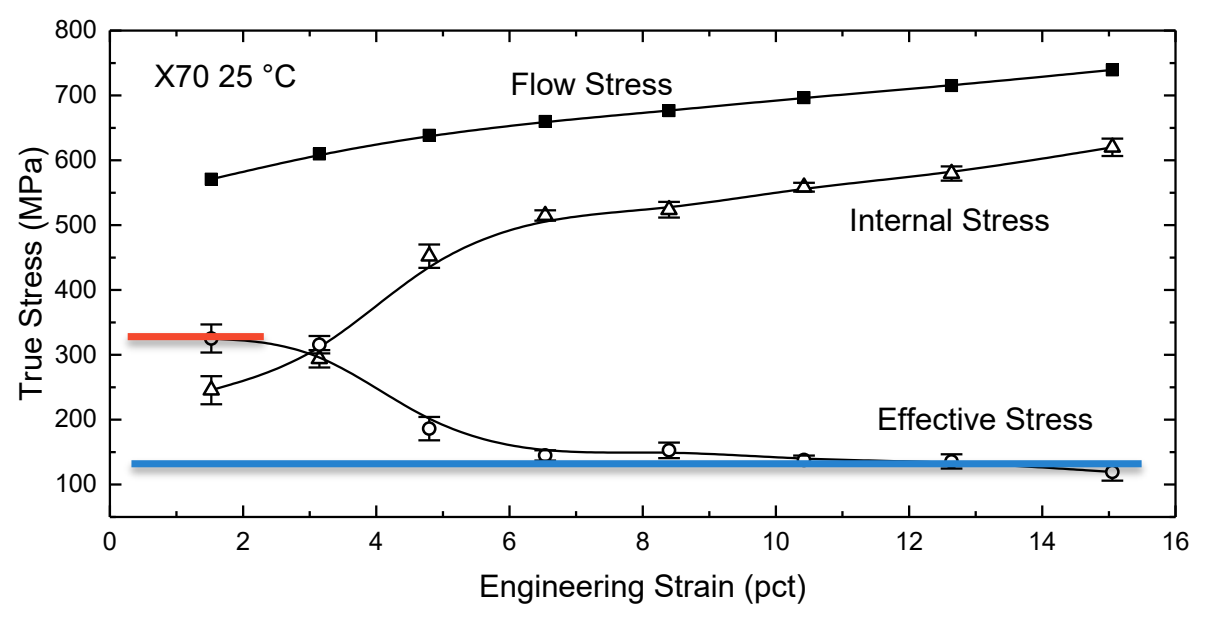

- Effective Stress:

- Max effective stress = $325 \mathrm{MPa}$

- $\mathrm{PN}+\mathrm{SS}+\mathrm{STA}=325 \mathrm{MPa}$

$-140 \mathrm{MPa}$ strength from solid solution strengthening and Peierls.

- $\mathrm{PN}+\mathrm{SS}=140 \mathrm{MPa}$

- Strength from static strain aging

- $325 \mathrm{MPa}-140 \mathrm{MPa}=185 \mathrm{MPa}$

Analysis can be supported with first principles calculations/modeling.

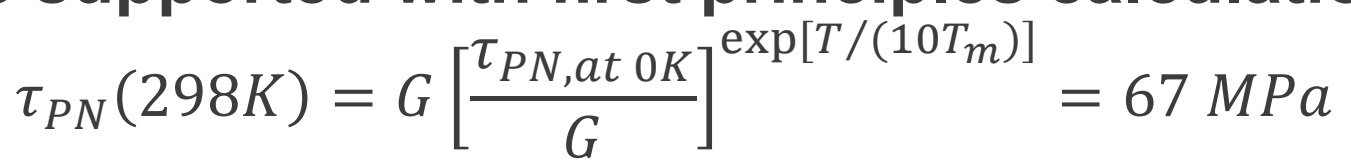

Solid solution strengthening model (Sum of P, Si, Cu, Mn, Ni, Mo, Cr) $=110 \mathrm{MPa}$ Static strain aging model $(C)=152 \mathrm{MPa}$ (static strain aging)

Total theoretical effective stress $=329 \mathrm{MPa}$ 


\section{How Might $\delta$-Pu Stress Relaxation Look?}

- Contributions to the effective stress:

$-\mathrm{Ga}$

- impurity atoms

- decay products (e.g $\mathrm{U}, \mathrm{He}$ in solution)

- Contributions to the internal stress:

-Forest dislocations (FCC)

- Grain boundaries

-Second phases (?)

- Decomposition of the delta phase to $\alpha$ $\mathrm{Pu}$ or $\mathrm{Pu}_{3} \mathrm{Ga}$ in aged samples.

- He bubbles (?)

- How does a dislocation interact with a $\mathrm{He}$ bubble?
- Activation volume

- Effective stress = minor contributions

- Internal stress = major contributions

- The presence of most defects will reduce the activation volume.

- Potential for use at LANL.

- Development of defects during aging.

- Quality of new material.

- Differences between cast and wrought product. 


\section{How does a Dislocation Interact with a Helium Bubble?}

- He is not very soluble in $\delta-P u$ and forms bubbles.

- Dislocations likely interact with bubbles in some way (similar to precipitation strengthening).

- Could dislocations shear through bubbles?

- Dislocations cannot pass through free surfaces or incoherent particles (looping mechanisms).

- Combination of stress relaxation and TEM

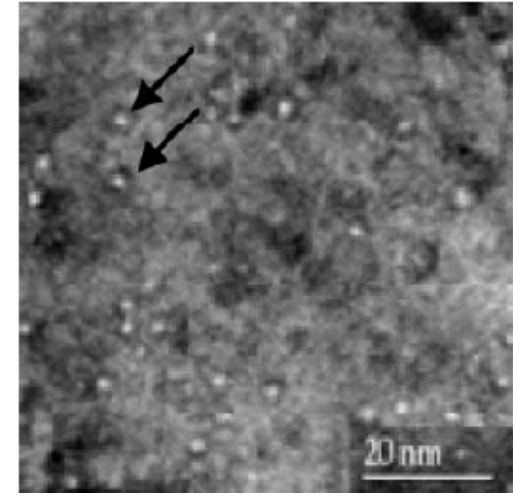

Schwartz et al. 2005 could help develop first principles concepts.

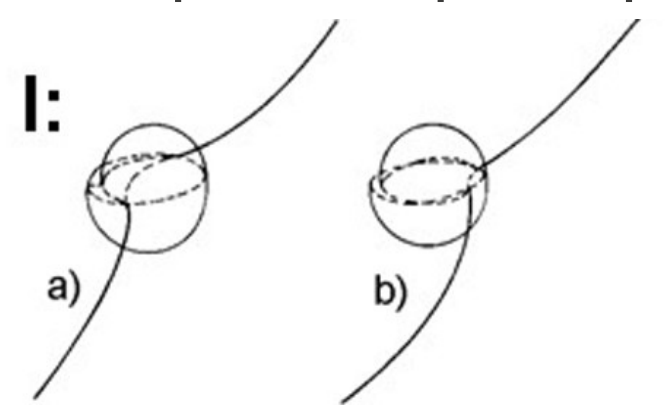

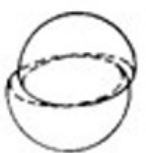

c)
II:

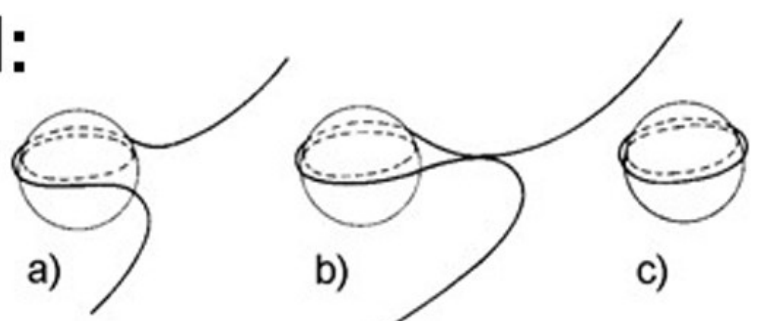




\section{Current Experimental Plan (LDRD-ECR)}

- Perform stress relaxation experiments on Pu samples in the MST-16 inventory to target microstructure/processing and aging effects.

- Ga concentrations ranging between 1-7 at pct.

- Microstructure differences in materials with similar age and composition.

- Samples with similar composition at ages ranging 0-20 years (also heat treatments to anneal out some aging related defects).

- Expected Results

- Ga predictably increases the effective stress.

- Grain size will influence the activation volume and internal stress.

- Aging = unknown .

-We have an opportunity to study strengthening mechanisms associated with aging. 


\section{Internal Friction}

(Using elastic deformation to study defect concentrations, activation energy, and diffusion kinetics)

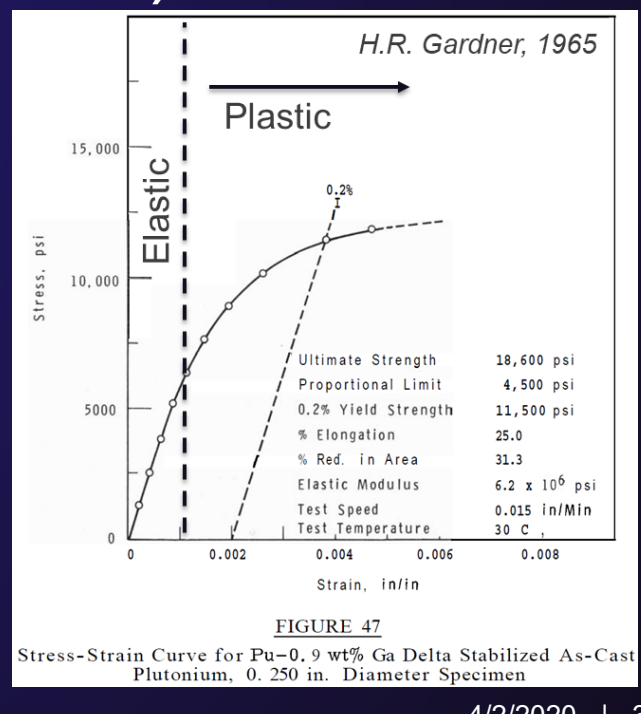




\section{History of Internal Friction Measurements (Guye, 1913)}

LE FROTTEMENT INTÉRIEUR DES SOLIDES; SES VARIATIONS AVEC LA TEMPÉRATURE $\left({ }^{1}\right)$;

Par M. Ch.-Eug. GUYE.

C'est en 1784 que Ch.-Aug. de Coulomb dotait la physique expérimentale du merveilleux instrument qu'est la balance de torsion. Les premières expériences sur l'amortissement des oscillations des fils métalliques qu'il fit alors, ouvrirent la voie aux nombreuses recherches qui ont été effectuées depuis $\left({ }^{2}\right)$. La science française s'est donc montrée dans ce domaine fidèle à ses belles traditions d'initiatrice.

Cependant, malgré l'ancienneté des recherches de Coulomb, malgré la simplicité apparente des dispositifs expérimentaux, mal-

It was in 1784 that Charles-Augustin de Coulomb endowed experimental physics of the wonderful instrument that is the balance of torsion. The first experiments on the damping of oscillations of metal wires he made then opened the way for which have been performed since Depuis (2). French science has so shown in this area faithful to its beautiful traditions of initiator. However, despite the age of Coulomb's research, despite the apparent simplicity of experimental devices, despite the large number of published works, many of which by illustrious scholars, the internal friction of the solids has not yet revealed its secrets, while so many other chapters of the have received satisfactory explanations. This is, as you know, the very complexity of the solid state, complexity which always appears bigger as and when that our knowledge in this area is increasing.

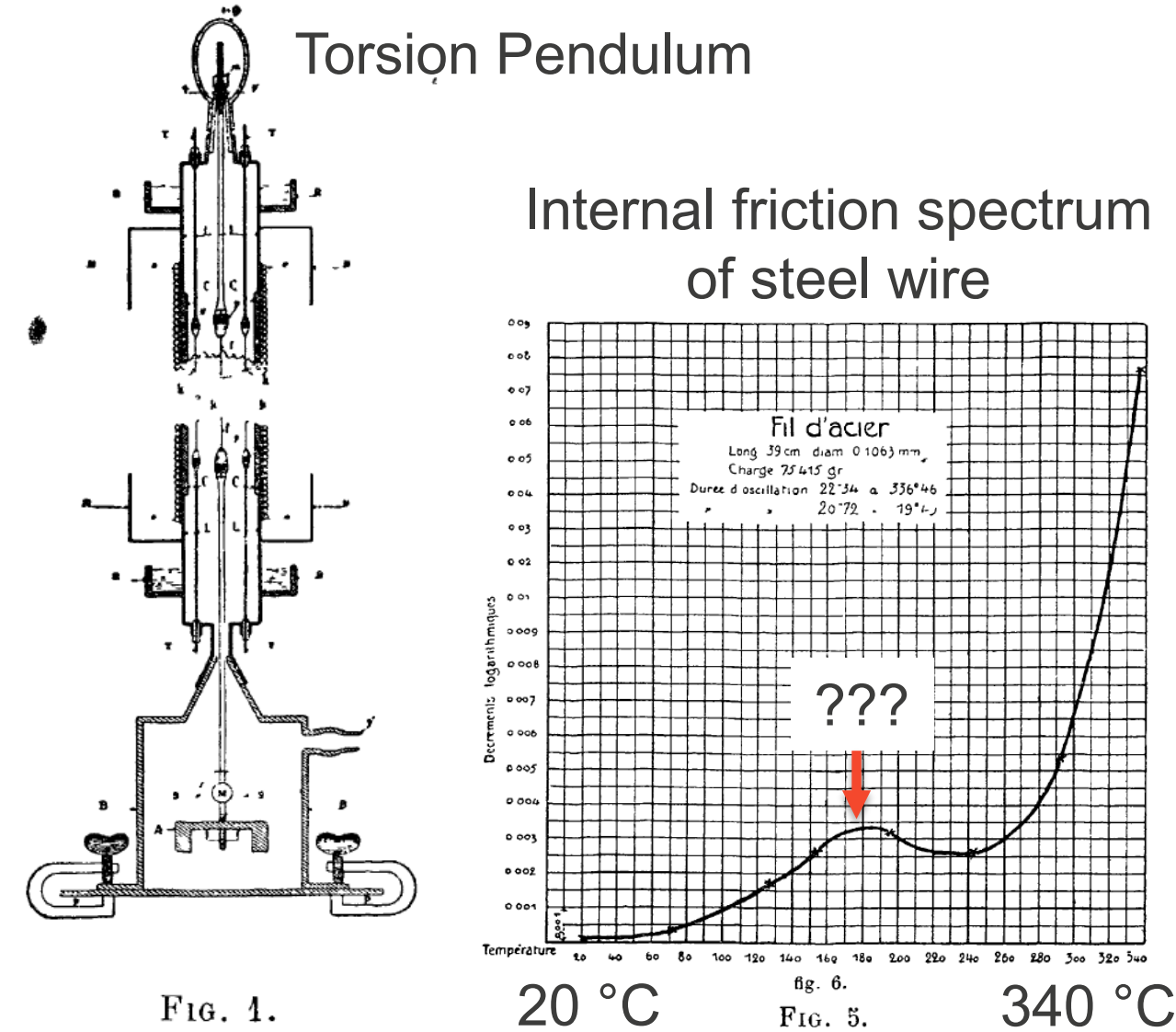

Snoek, 1939: Peak related to carbon interstitial atom mobility. 


\section{Measurement of Internal Friction $\left(Q^{-1}\right.$ or $\left.\tan \delta\right)$}

- Resonant: $10^{3}-10^{7} \mathrm{~Hz}$

-Free decay vibration.

- Resonant ultrasound spectroscopy.

- Subresonant: $10^{-4}-10^{2} \mathrm{~Hz}$

- Forced torsion pendulum.

- Dynamic mechanical analyzer.
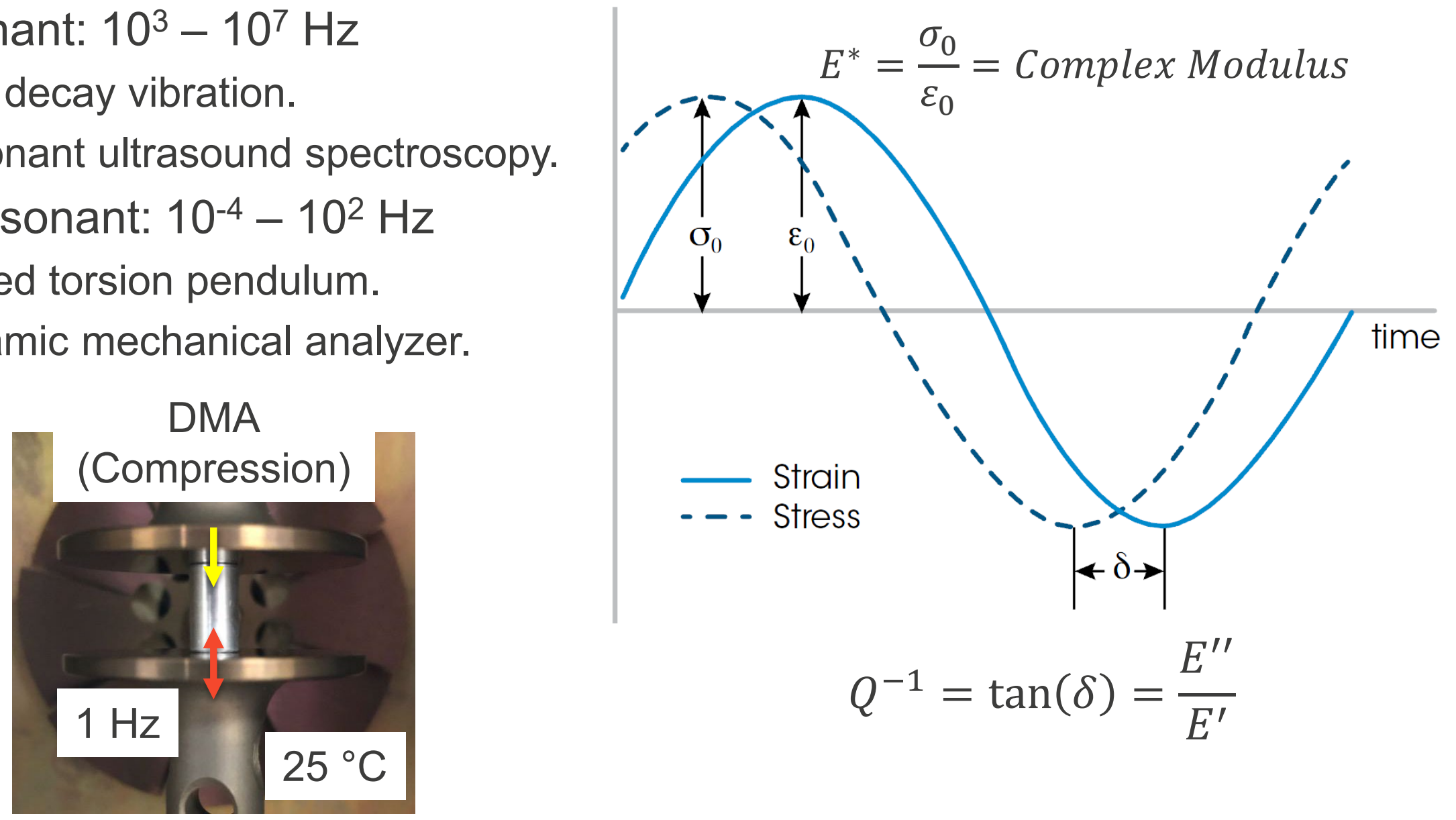

$$
Q^{-1}=\tan (\delta)=\frac{E^{\prime \prime}}{E^{\prime}}
$$




\section{Mobile Defects in Metal}

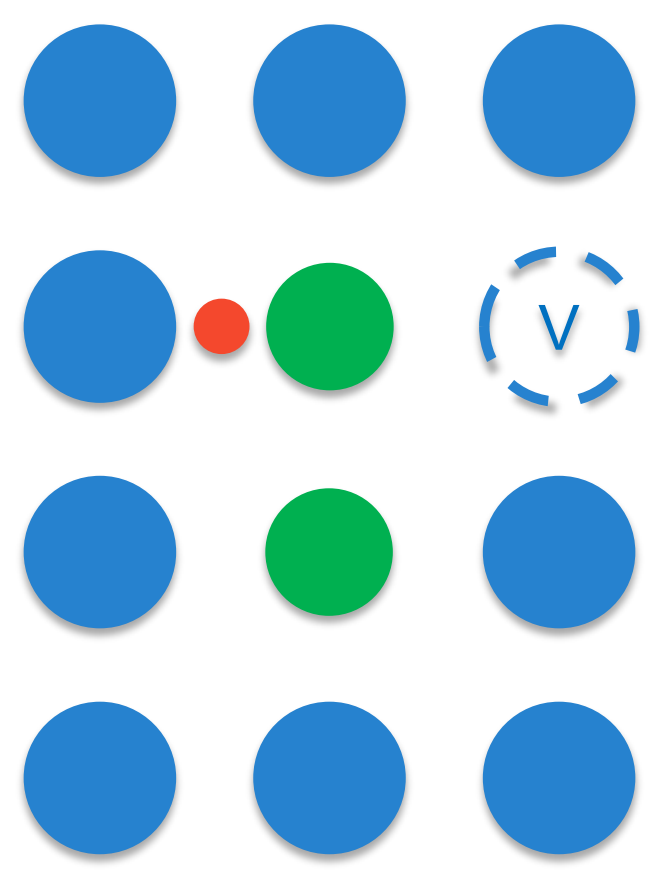

- Can be sub-int, sub-sub, or int-int.

- Experimental measurement of $\mathrm{Ga}-\mathrm{Ga}$ mobility in Pu very likely. 


\section{Mobile Defects in Metal}
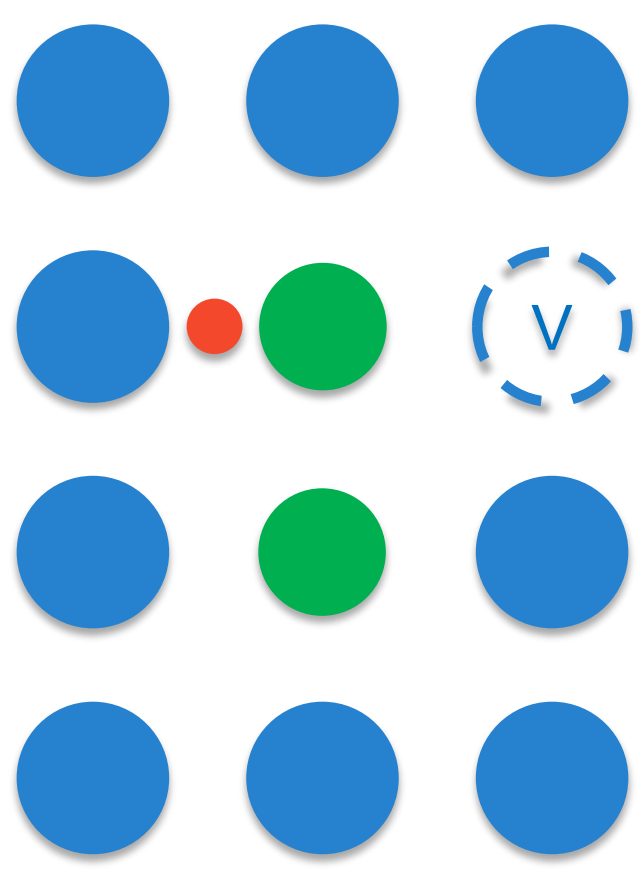
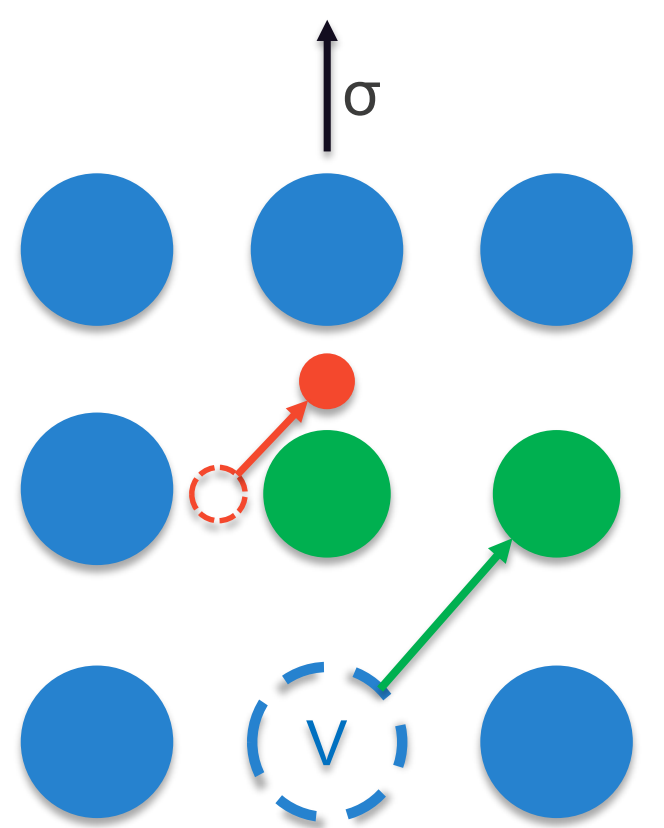

- Very common peak in fcc.

- Can be sub-int, sub-sub, or int-int.

- Experimental measurement of Ga-Ga mobility in Pu very likely. 


\section{Example Internal Friction Data}

- $\mathrm{Q}^{-1}$ Measured at various $\mathrm{T}$ and $\mathrm{f}$.

- Peaks in the spectra:

- Maximum vibrational dampening when defects move at the same rate as the vibrational frequency.

- Peak Analysis:

- Peak shifts $\rightarrow$ Diffusivity, activation energy, and residence time.

- Experimental validation of DFT modeling?

- Can support Ga homogenization.

- Peak height a defect concentration (semi-quantitative).

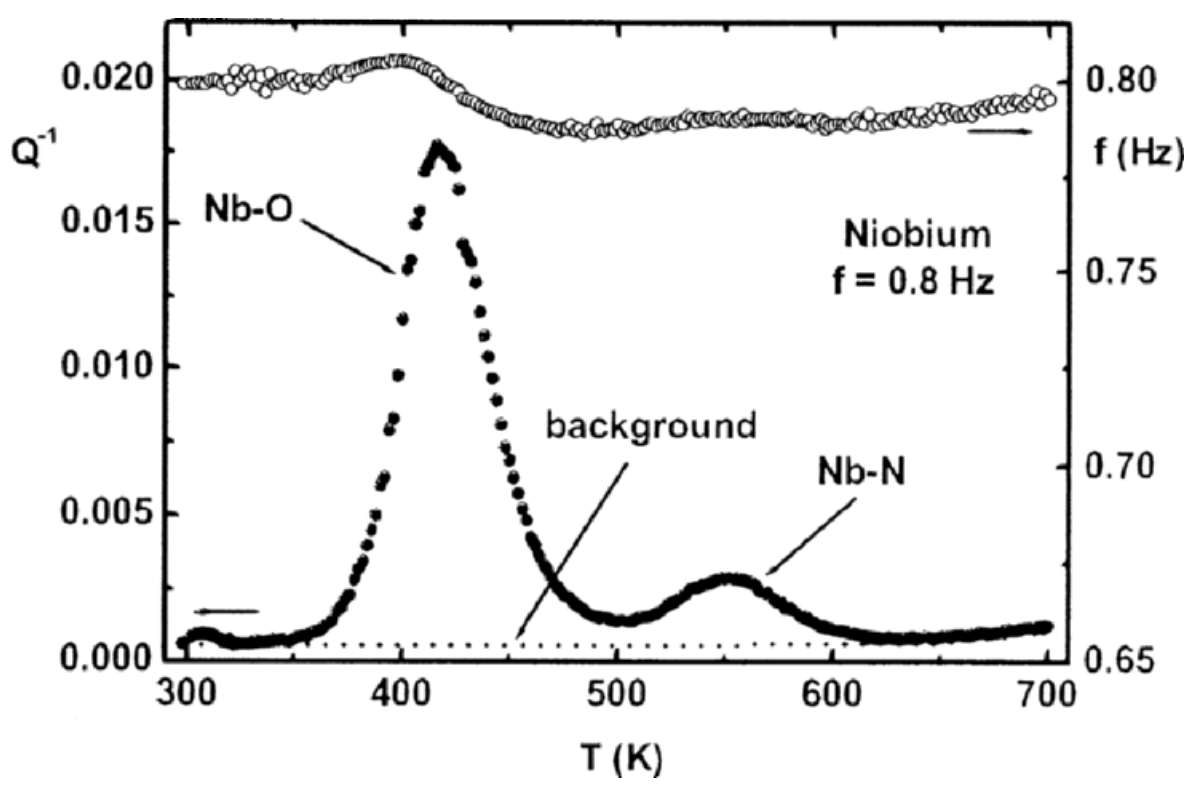

- Not possible with any other technique for certain defects! 


\section{Ultimate Goal: Internal Friction Testing of Pu-Ga Alloys}

- $\delta-P u=f c c$

- Ga likely substitutional point defect.

- $\mathrm{H}$ and $\mathrm{He}$ interstitials.

- Other point defects from radioactive decay/aging or impurity elements.

- Dislocations and grain boundaries.

- Phase transformations to $\varepsilon$ (high T) or $\alpha^{\prime}$ (low T).

- $\mathrm{T}_{\mathrm{m}}=640-700{ }^{\circ} \mathrm{C}(913-973 \mathrm{~K})$.

- First principles theoretical creep:

- $0.5 \mathrm{~T}_{\mathrm{m}}=184-214^{\circ} \mathrm{C}(457-487 \mathrm{~K})$.

- Pu AGING CAN INFLUENCE DEFECTS.

- Internal friction can detect what is listed above.

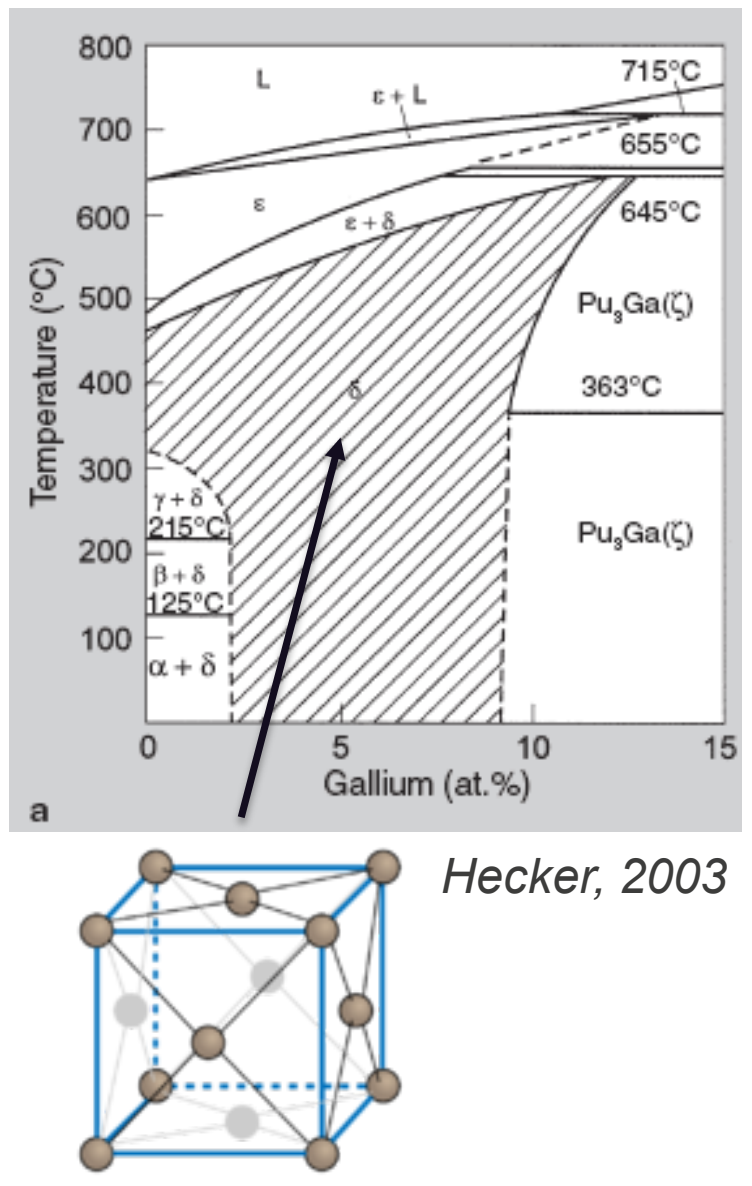




\section{What Internal Friction Peaks are in fcc Pu-Ga?}

- We don't know! Very little experimentation has been done on Pu. - Nothing on Pu-Ga.

- Magnitude of dampening from moving defects is material and crystal structure dependent.

- What might we see (recall from earlier):

- Point defects ( $\mathrm{Ga}, \mathrm{He}$, and radioactive decay/impurity elements).

- Creep and vacancy diffusion.

- Dislocations.

- Phase transformations: $\delta \rightarrow \varepsilon$ or $\delta \rightarrow \alpha^{\prime}$. 


\section{Phase Transformations}
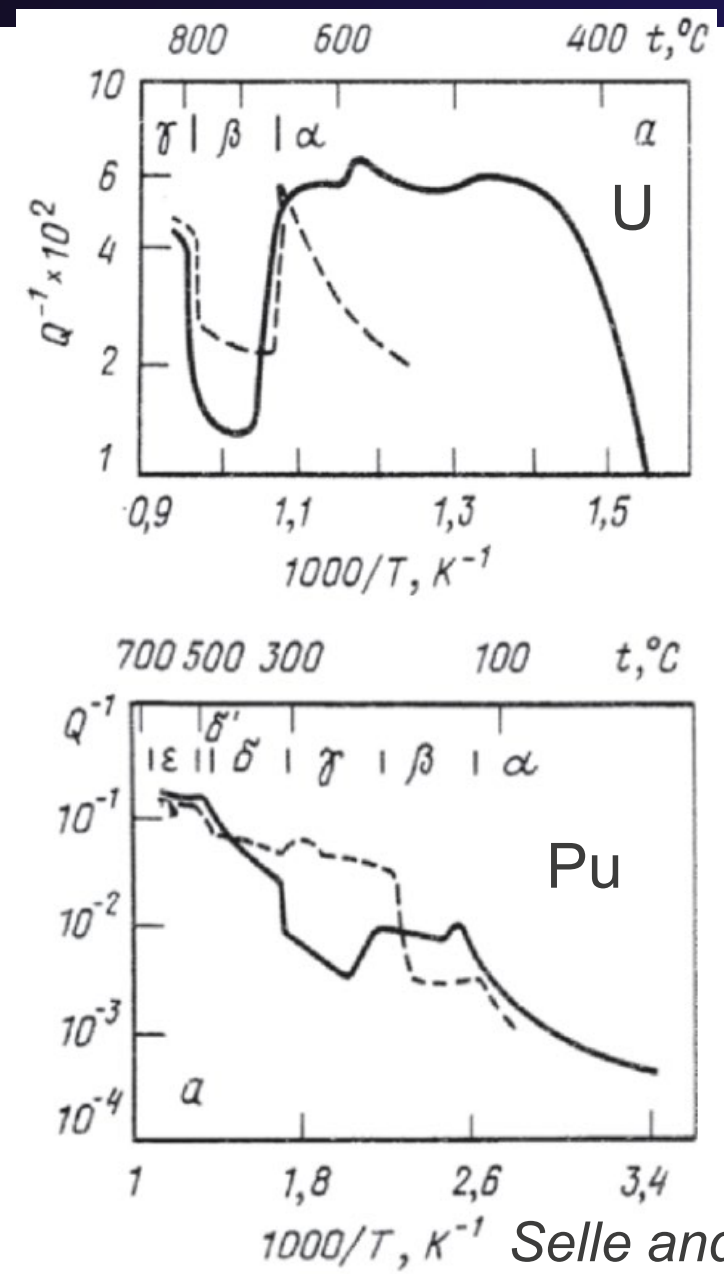

- First verified using Co, U, and Pu!!!

- Distinguish shear vs diffusional phase transformations.

- Diffusional $=$ Large jump in $\mathrm{Q}^{-1}$.

- Shear $=$ small peak with no large change in $Q^{-1}$.

- U

- All diffusion based transformations.

- $\mathrm{Pu}$

- Shear $=\alpha \rightarrow \beta ; \delta \rightarrow \delta ; \delta \rightarrow \varepsilon$

- Diffusion $=\beta \rightarrow \gamma ; \gamma \rightarrow \delta$ 


\section{Cold Experiments Relevant to fcc Pu-Ga}




\section{Internal Friction Instrumentation (Possibilities for PF-4)}

- Standard DMA's (<20 N of force)

- Low forces require metals to be tested in bending.

- Small machine footprint.

- High $Q^{-1}$ resolution.

- High force DMA (<500 N of force).

- Ideal Pu geometry = compression!

- Test to see if $\mathrm{Q}^{-1}$ of low stiffness metals can be measured in compression.

- Larger machine footprint.

- Good but lower $\mathrm{Q}^{-1}$ resolution.

- Torsion Pendulum

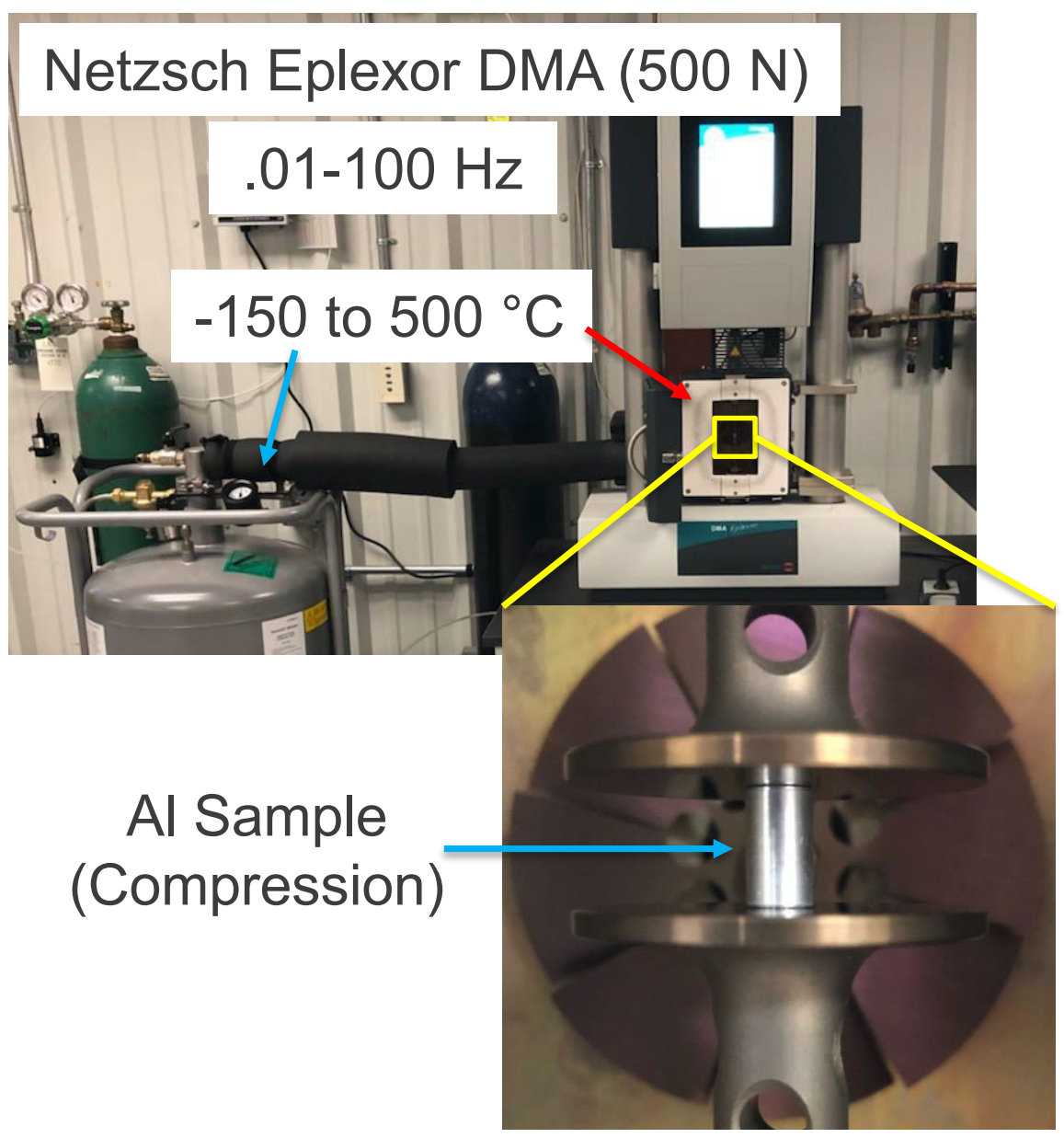

- Requires development from scratch.

- Best way to measure $\mathrm{Q}^{-1}$ in metals. 


\section{Annealed $1100 \mathrm{Al}$ in Compression}

- $\mathrm{Al}=\mathrm{fcc}$

- Stiffness is comparable to $\delta-P u$.

- Up to 1 at pct of $\mathrm{Si}+\mathrm{Fe}+\mathrm{Cu}$ substitutionals.

- Peaks:

$-150{ }^{\circ} \mathrm{C}$ : poor signal to noise ratio.

$-300^{\circ} \mathrm{C}$ : poor signal to noise ratio.

$-350^{\circ} \mathrm{C}$ : excellent signal. Creep related.

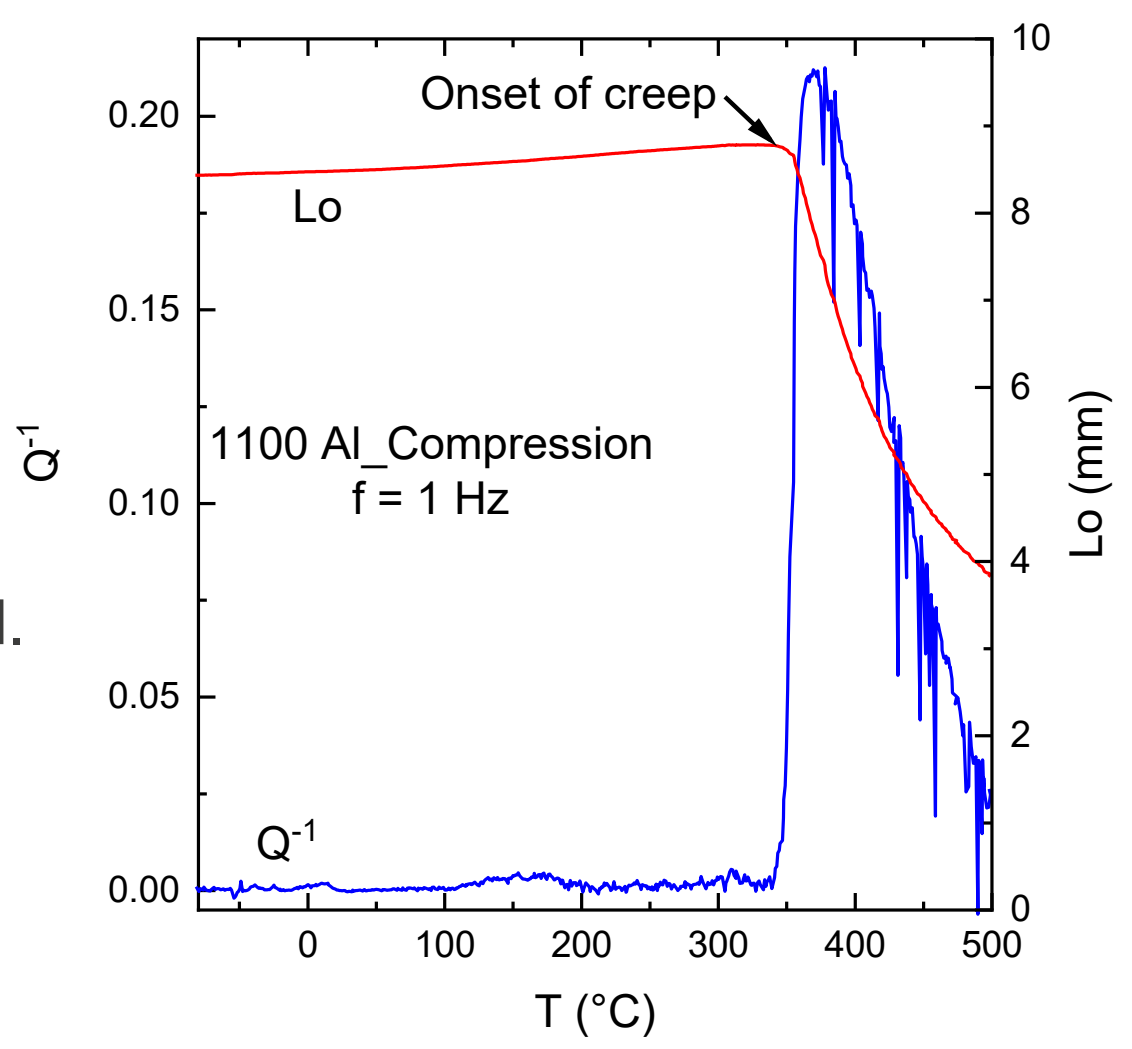




\section{Annealed $1100 \mathrm{Al}$ in Bending}

- Some peak temperature shifts:

$-150{ }^{\circ} \mathrm{C} \rightarrow 90^{\circ} \mathrm{C}$

$-300{ }^{\circ} \mathrm{C} \rightarrow 350^{\circ} \mathrm{C}$

$-350{ }^{\circ} \mathrm{C} \rightarrow>500^{\circ} \mathrm{C}$ (could be in a different creep condition).

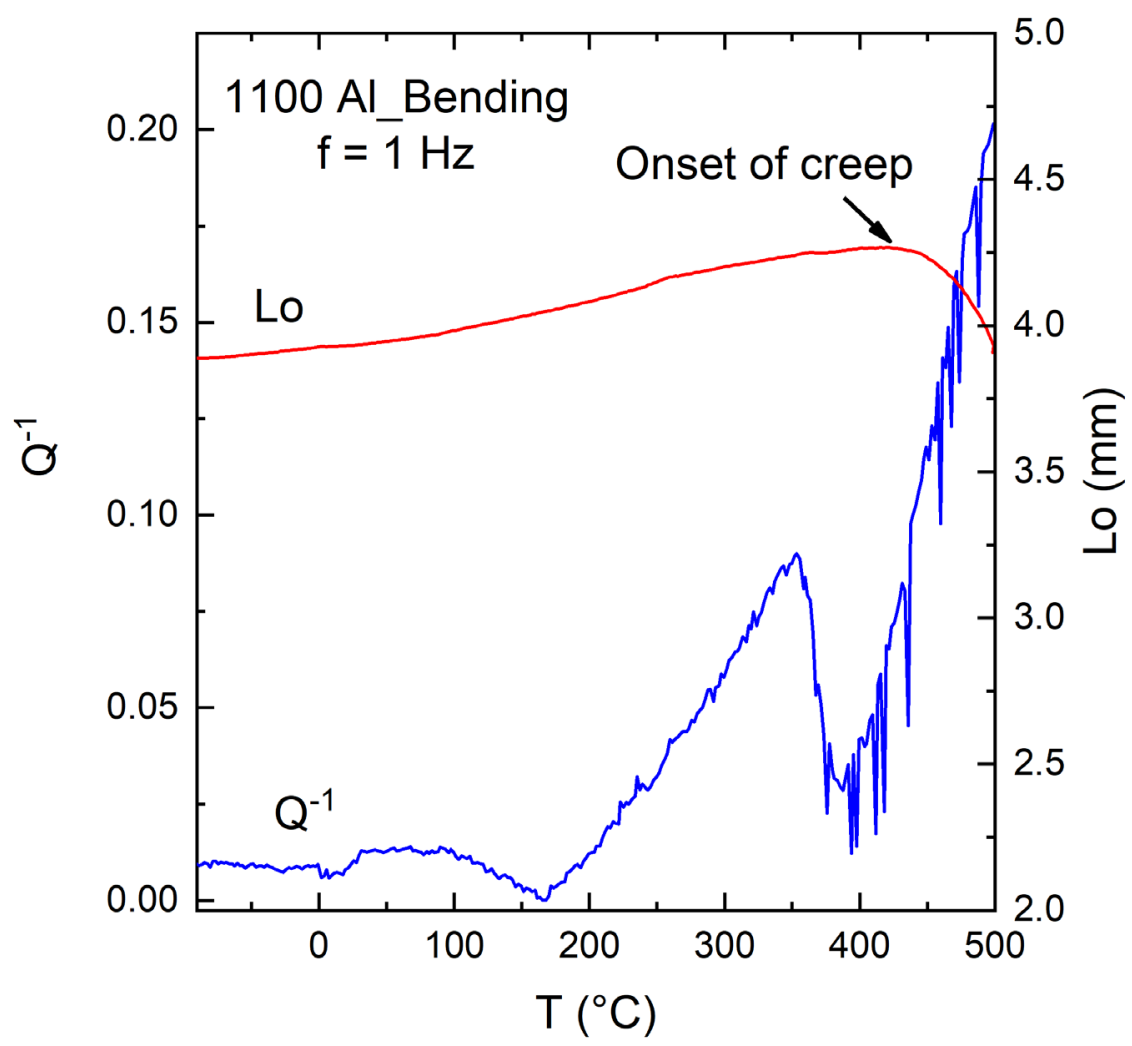




\section{Al Frequency Shift of Low Temperature Peak}

- Changing frequency causes a shift in peak temperature.

- Apparent activation energy $(\mathrm{H})$ :

$-\ln \left(\frac{f_{2}}{f_{1}}\right)=\frac{H}{k}\left(\frac{1}{T_{1}}-\frac{1}{T_{2}}\right)$

$-\mathrm{H}=0.78 \pm 0.26 \mathrm{eV}$

- Mean residence time $(\tau)$ :

$-\tau e^{(H / k T)}(2 \pi f)=1.0$

$-\tau=9.0 \times 10^{-13} \pm 2.0 \times 10^{-13} \mathrm{~s}$

- Urreta de Pereya et al (1987):

- Si-Dislocation Reorientation

$-\mathrm{T}=87^{\circ} \mathrm{C}$ at $1 \mathrm{~Hz}$

$-\mathrm{H}=0.82 \mathrm{eV} ; \tau=10^{-12} \mathrm{~s}$

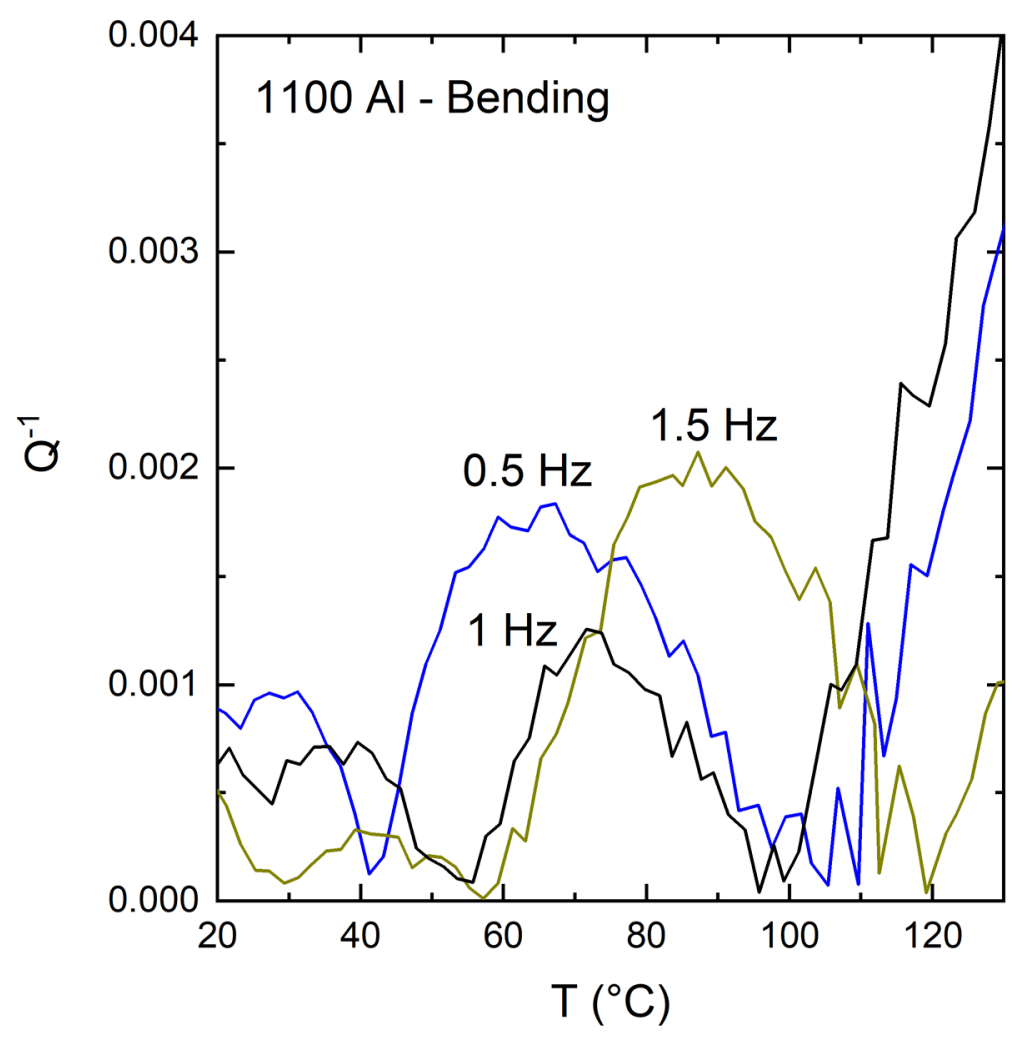




\section{Conclusions and Recommendations for PF-4}

- Internal friction measurements in compression mode were fairly successful with $1100 \mathrm{Al}$.

- Creep analysis is possible in different deformation mechanism regions using the high force DMA.

- Not enough sensitivity for lower intensity peaks.

- Internal friction measurements in bending mode were significantly more sensitive than compression.

- Measured activation energy and mean residence time values of a low intensity peak match reported Si-dislocation peak from the literature.

- Proposal for upcoming Pu measurements.

- A standard DMA is a better choice for Pu internal friction measurements.

- Low force capabilities will require unique samples for DMA.

- The instrument will be easier to incorporate in PF-4 due to its smaller size. 


\section{Thank you tayiacobs@lanl.gov 505-667-8234}




\section{Material Properties}

- Shear modulus at RT = 15.8 GPa

- Yield strength = $128 \mathrm{MPa}$ (Gardner)

- Berger's Vector = 3.28 x 10-10 m (Kaschner and Hecker, 1999) 


\section{Acknowledgements}

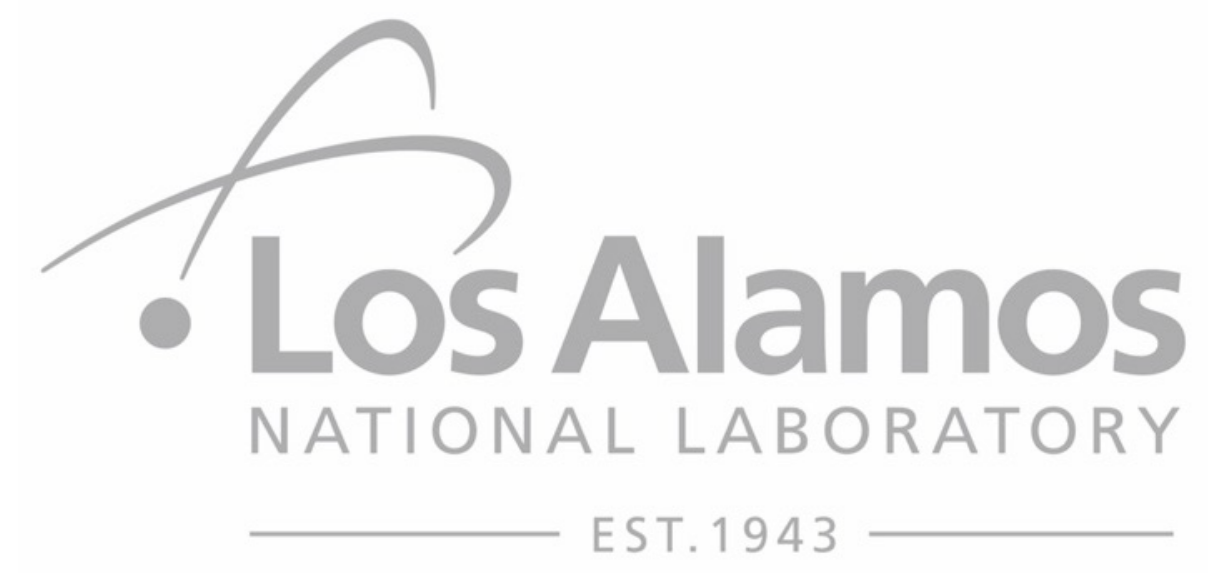

- Seth Imhoff

- Meghan Gibbs

- Clarissa Yablinsky

- Jeremy Mitchell

- Sendin Bajric

- Sven Vogel

- Eunice Solis

- Chris Baxter

- Moyra Gutierrez

- Mark Ortega

- Matt Schneider

- Paul Tobash

- Mark Wartenbe
- Gabrielle Kral

- Karen Chen 


\section{Definition of Internal Friction}

- Dissipation of mechanical energy inside a gaseous, liquid, or solid medium (Blanter et al., 2007).

- In solids: energy dissipation connected with deviations from Hooke's Law.

- Hooke's Law $\rightarrow$ Elastic Deformation.

- Energy dissipation is time dependent.

- Time dependent elastic deformation = Anelastic deformation.

- Main source of internal friction. 


\section{Anelasticity}

- Time dependent component of fully recoverable elastic deformation.

- All materials experience anelastic deformation.

- Anelastic deformation can be amplified by the movement of defects within the material.

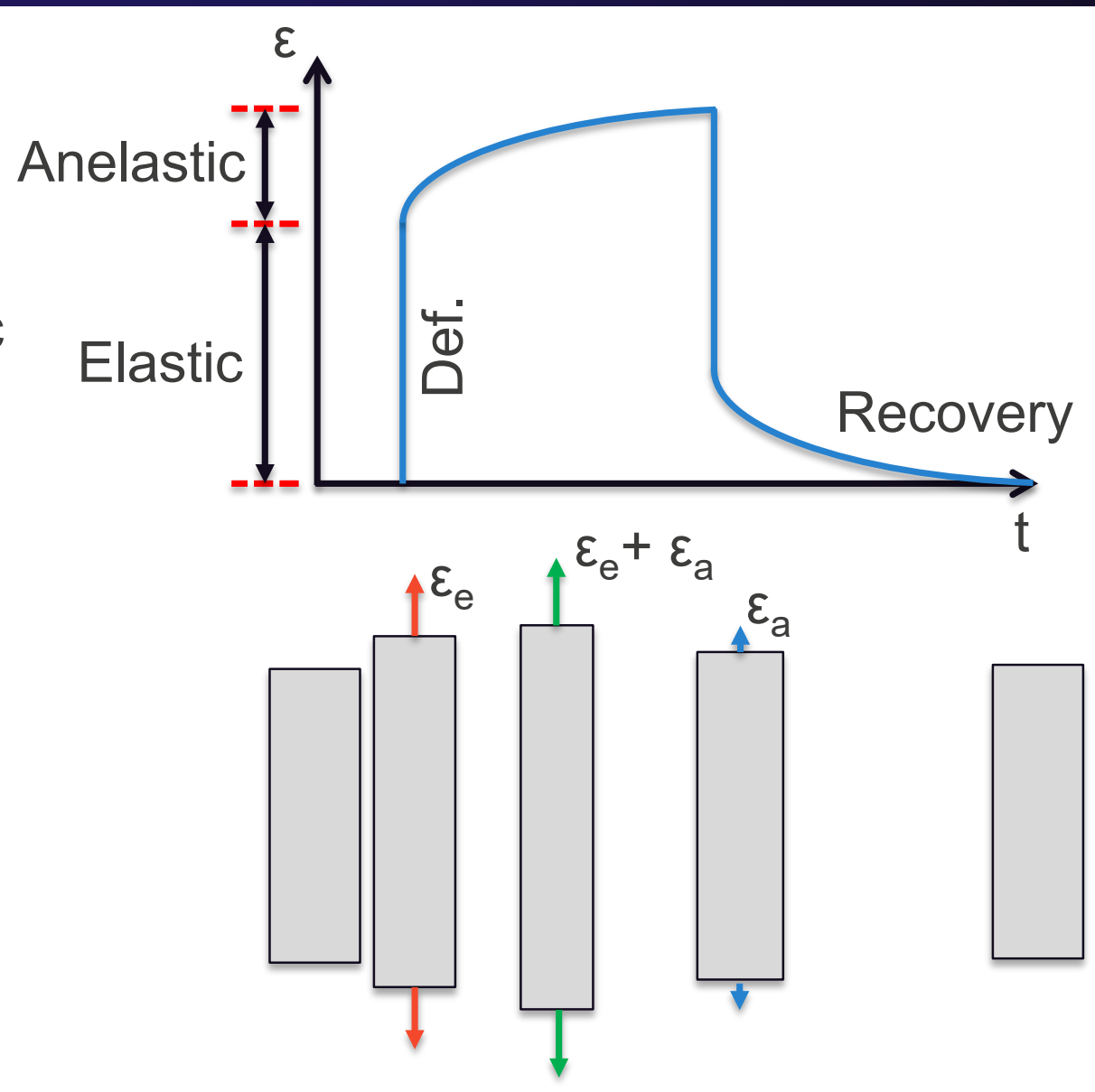




\section{Pu Aging: We do not understand the impact of radiogenic processes on plutonium.}

Pu nuclear decay processes:

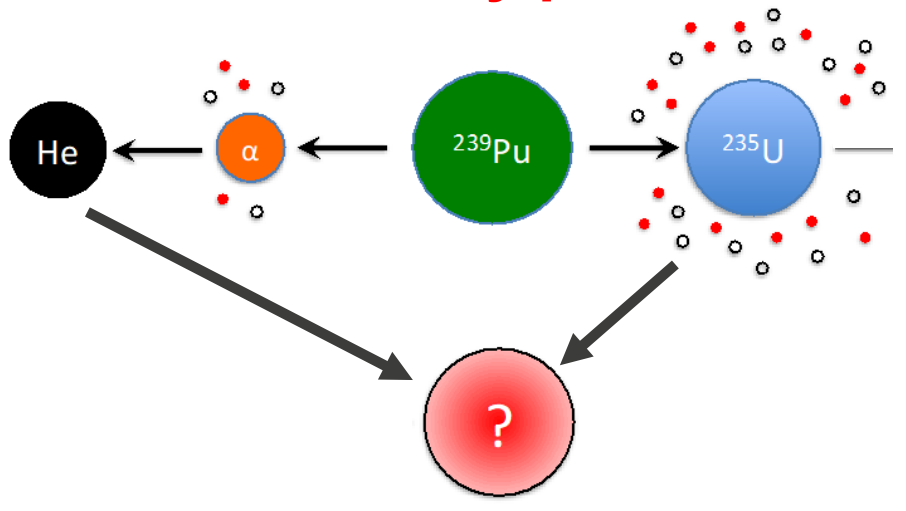

Void swelling, bubble formation, daughter product ingrowth and unwanted phases.

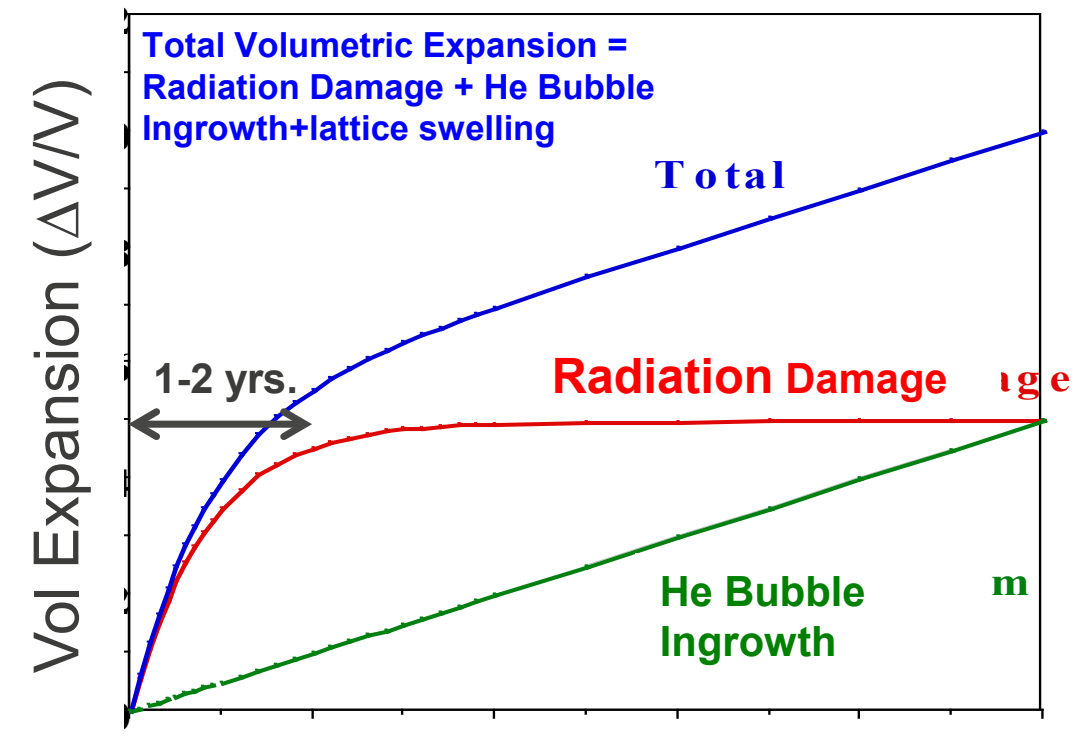

Damage (dpa) or Age (t)

If $\delta$-Pu radiogenically aged like other FCC alloys (e.g. austenitic steel), then catastrophic void swelling would occur after 20-40 years.

Studies have not detected void swelling in Pu-Ga alloys as old as $\mathbf{5 0}$ yrs. Why not? Will they swell? 


\section{Creep Relaxations (very high $\mathbf{Q}^{-1}$ )}

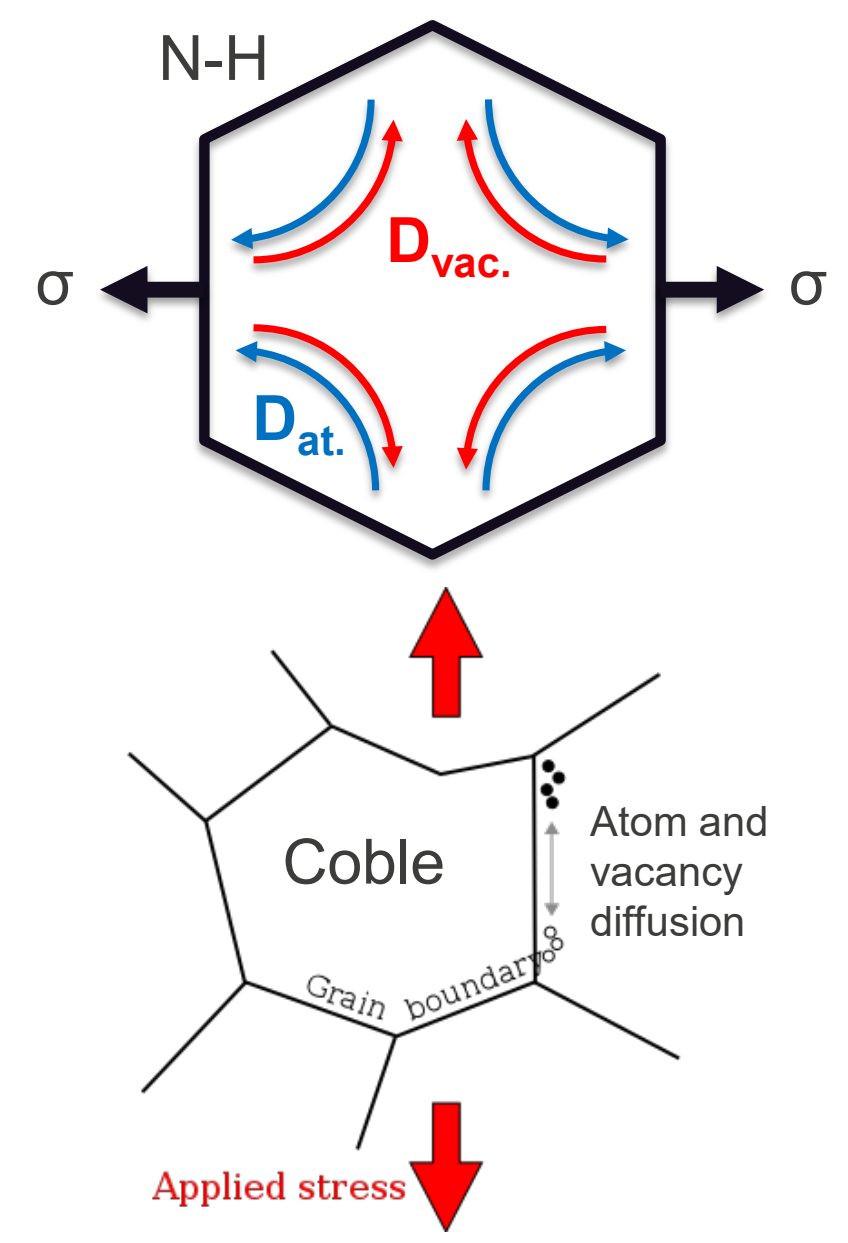

- Possible to distinguish between creep mechanisms (material-microstructure dependent).

- Coble vs N-H vs dislocation creep.

- Measurements of vacancy diffusion.

- Likely observed in Pu with Netzsch DMA.

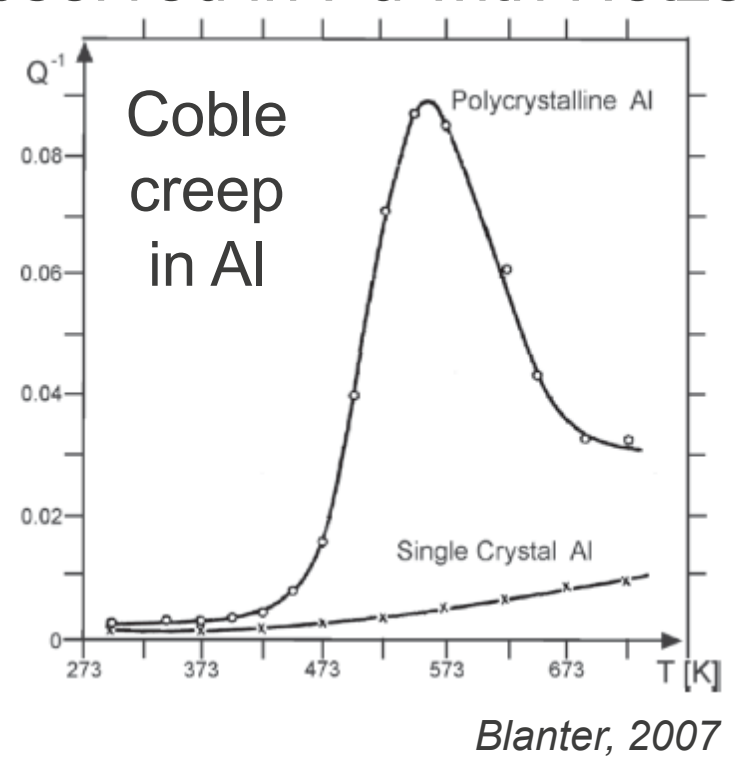




\section{Annealed $1100 \mathrm{Al}$ in Compression}

- $\mathrm{Al}=\mathrm{fcc}$

- Stiffness is comparable to $\delta-P u$.

- Up to 1 at pct of $\mathrm{Si}+\mathrm{Fe}+\mathrm{Cu}$ substitutionals.
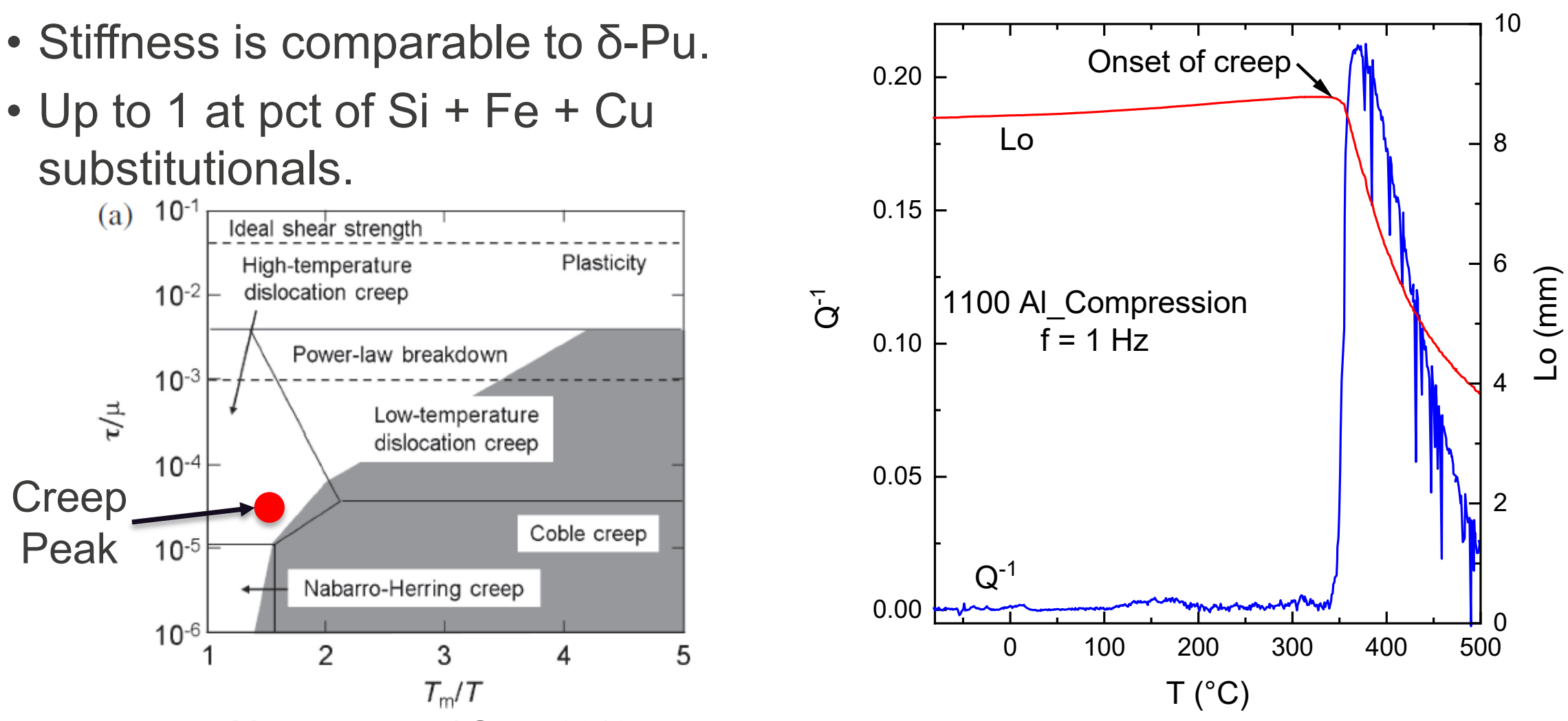

Matsunaga and Sato, 2013 


\section{Annealed $1100 \mathrm{Al}$ in Bending}

- Some peak temperature shifts:

$-150{ }^{\circ} \mathrm{C} \rightarrow 90^{\circ} \mathrm{C}$

$-300{ }^{\circ} \mathrm{C} \rightarrow 350^{\circ} \mathrm{C}$

$-350{ }^{\circ} \mathrm{C} \rightarrow>500^{\circ} \mathrm{C}$ (could be in a different creep condition).
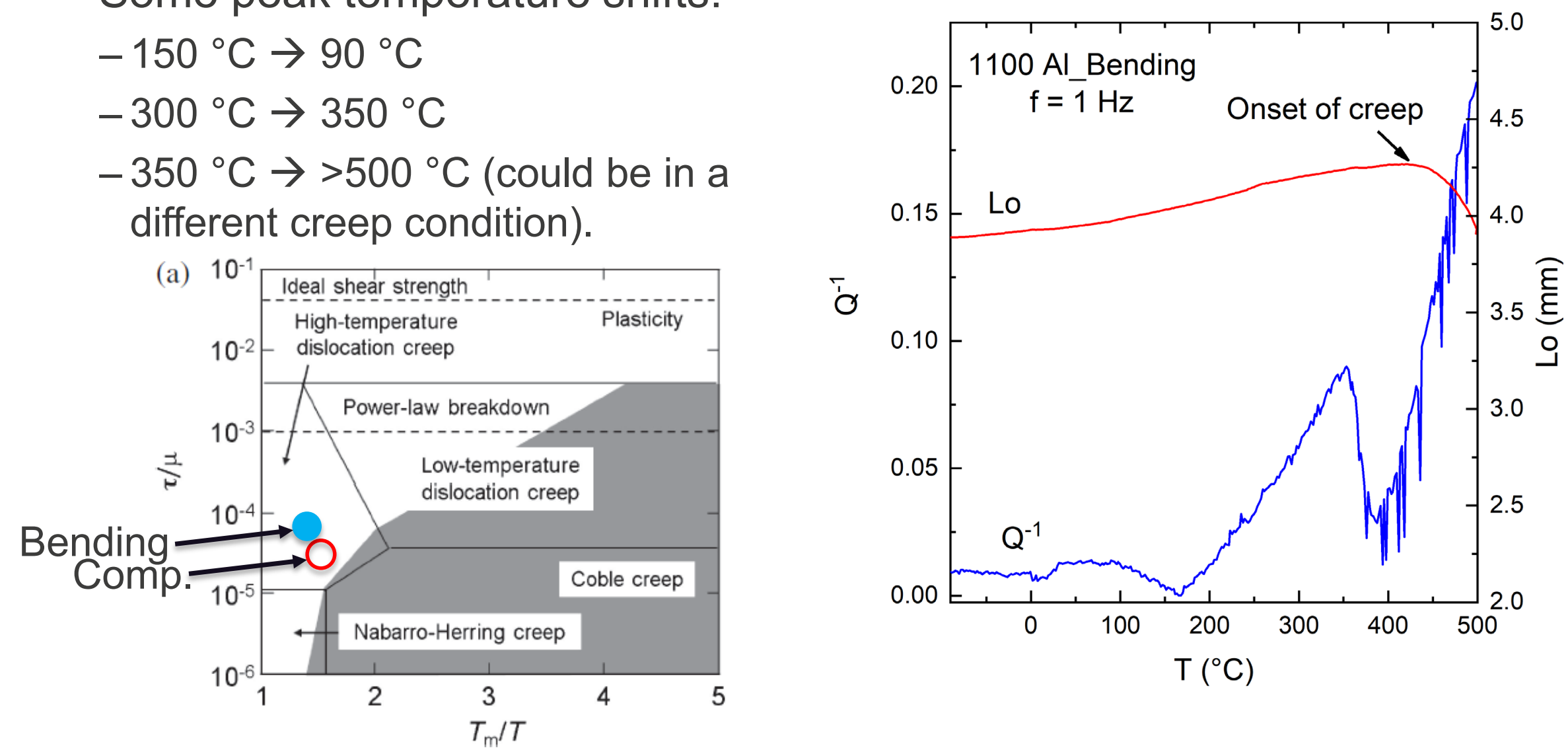


\section{Static Strain aging schematic}

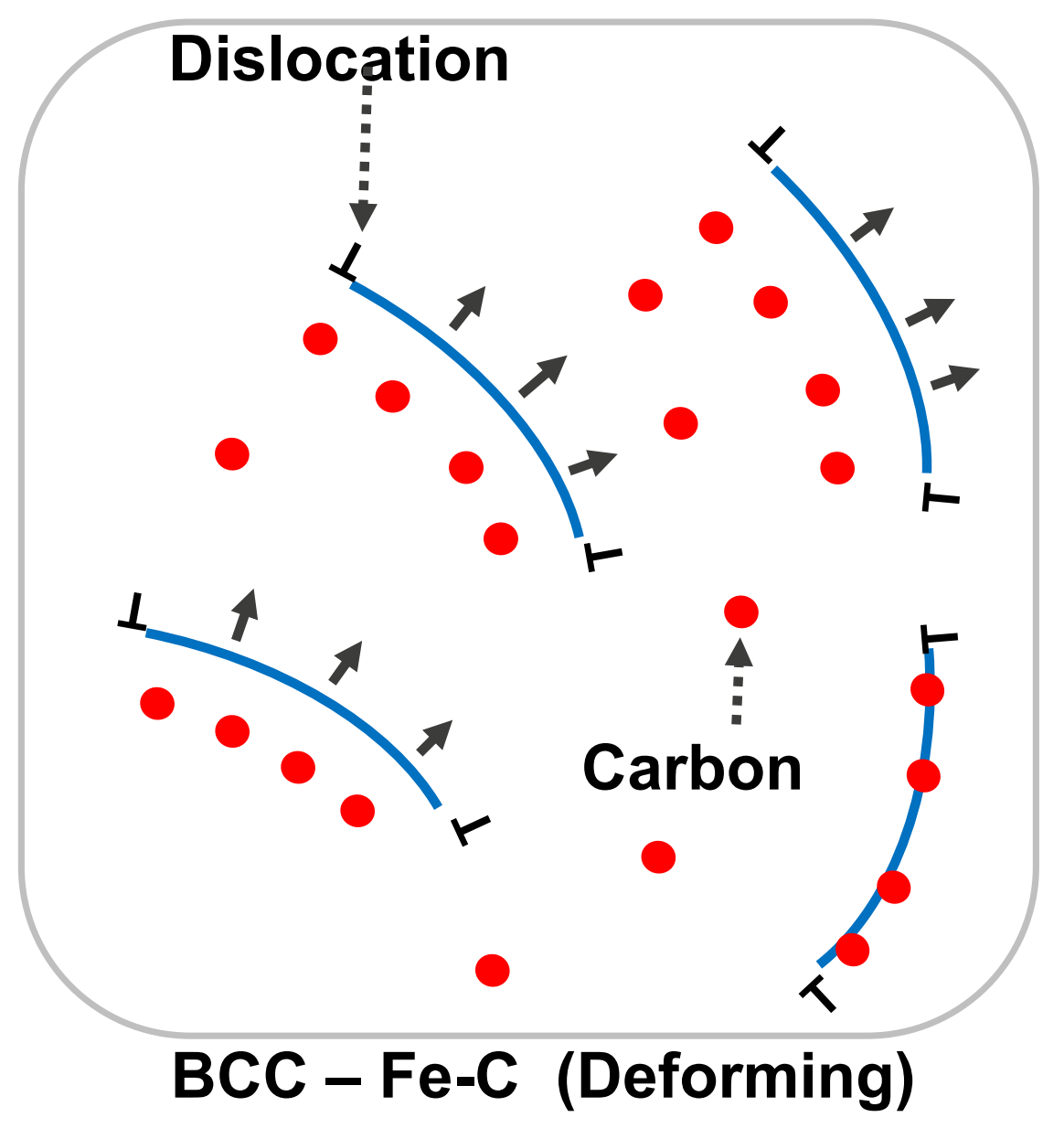

